\title{
Polylactic acid-lauryl functionalized nanocellulose nanocomposites: Microstructural, thermo-mechanical and gas transport properties
}

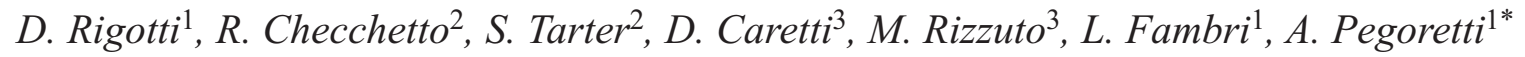 \\ ${ }^{1}$ University of Trento, Department of Industrial Engineering, Via Sommarive 9, Trento, Italy \\ ${ }^{2}$ University of Trento, Department of Physics, Via Sommarive, 14, Trento, Italy \\ ${ }^{3}$ University of Bologna, Department of Industrial Chemistry 'Toso Montanari’ Viale del Risorgimento 4, Bologna, Italy
}

Received 24 January 2019; accepted in revised form 13 May 2019

\begin{abstract}
Thermo-mechanical and gas transport properties of polylactic acid (PLA) matrix containing various amounts (from 1 to $20 \mathrm{wt} \%$ ) of nanocellulose esterified with lauryl chains (LNC) were investigated on solvent cast film of about 50 micron. Scanning electron microscopy indicated that, up to a filler content of $6.5 \mathrm{wt} \%$, LNC was well dispersed or formed small, sub-micrometric clusters. At higher filler contents, oval aggregates in the micrometric range were detected. The addition of LNC did not change the matrix glass transition temperature and melting temperature. Concurrently, as LNC content increased, both elastic and storage moduli at room temperature exhibited a sharp decrease up to $5 \mathrm{wt} \%$ of filler, and a lower reduction for LCN concentration of 10-20 wt.\%. Nanocomposites with 3 and $5 \mathrm{wt} \%$ of LNC showed the highest strain at break and a large amount of plastic deformation due to a strong interfacial adhesion between the PLA and filler particles. For higher LNC fractions the presence of aggregates weakened the nanocomposite leading to lower values of maximum stress and strain at break. With the addition of LNC particles, gas barrier properties of the PLA film versus deuterium, nitrogen and carbon dioxide were improved up to a critical LNC concentration of $6.5 \mathrm{wt} \%$, where the gas permeability of the nanocomposite resulted to be $70 \%$ lower than that of the PLA matrix. At higher filler contents, large LNC aggregates increased the gas permeability of the nanocomposites.
\end{abstract}

Keywords: biopolymer nanocomposites, polylactic acid, nano-cellulose, mechanical properties, gas barrier properties

\section{Introduction}

According to the European Bioplastics association, in 2017 , the so-called bioplastics represented only 2.06 million tons of the 320 million tons of plastics produced annually [1]. The global production capacity is expected to increase up to 2.62 million tons in 2023. This growth is pushed by the demand of more sophisticated biopolymers, new applications and products. From packaging, agriculture, consumer electronics, textile to automotive, bioplastics are used in an increasing number of applications. In fact, biopolymers offer a number of additional advantages if compared to conventional plastics, such as a reduced carbon footprint and additional waste management options. Among bio-based and biodegradable plastics, polylactic acid (PLA) is one of the most interesting ones due to their good mechanical properties, good workability, excellent barrier properties. Therefore, it is a good candidate for the replacement of polystyrene (PS), polypropylene (PP), and acrylonitrile butadiene styrene (ABS) in many applications. However, PLA presents some weak points mainly represented by its low ductility, poor toughness, low glass transition temperature, high sensitivity to moisture and relatively low gas barrier, that limit its use in packaging applications $[2,3]$. Indeed, the main 
application of bioplastics is in the packaging industry, where cheap biodegradable materials with barrier properties against the permeation of gas, moisture, small molecules are progressively requested. The application of polymers in food packaging has focused the research about the possibility to limit the permeation of small molecules through the polymers.

The characterization of the gas barrier characteristic of a polymer is a key feature to determine the product-package shelf-life. The specific barrier properties of the packaging material are related to the product characteristics and the intended end-use application [4]. The synthesis of biopolymer nanocomposites containing inorganic nanoparticles (such as nano-clay or montmorillonite), metal and metal oxide nanoparticles (such as $\mathrm{Ag}, \mathrm{ZnO}$ and $\mathrm{CuO}$ ) and bio-additives (such as plant extracts, chitosan and cellulose) is a route often employed to improve the operative performance of biopolymers [5]. PLA-based bio-nanocomposites with enhanced gas barrier properties have been prepared adding nanoparticles such as $\mathrm{CaCO}_{3}[6]$ and $\mathrm{Cu}: \mathrm{ZnO}$ powders functionalized with $\mathrm{Ag}$ nanoparticles [7]. Cellulose fibers have been found to increase the barrier properties of thermoplastic biopolymer films against water [8], water vapor [9], air and oxygen [10]. The incorporation of nanocellulose functionalized with long chain aliphatic molecules [11] or with surfactants [12] in cast PLA films has been proved to better decrease the water vapor permeability with respect to pristine nanocellulose, due to an enhanced dispersion in the polymer matrix.

The use of natural or synthetic fibers is well contemplated to obtain specific characteristics and major improvements of the final properties of PLA [13]. Natural fibers offer several advantages over synthetic fibers due to their characteristics of renewability and biodegradability. This make natural fibers a good candidate as fillers in composite made by biopolymers. In particular, great attention was paid to the preparation of bio-composite made by PLA and different types of natural fibers such as flax [14-17], kenaf [18-20], jute [21-23], hemp [24], palm fibers [25]. However, some drawbacks are needed to be solved for the expansion of these bio-composite like limited mechanical durability, excess water absorption and poor thermal properties [26]. Natural fibers consist of repeated crystalline structure made by the aggregation of cellulose chains. The isolation of these ordered blocks of molecules lead to a new group of micro and nano fibers with enhanced properties [27].
Nanocellulose fibers have attracted significant interest in the scientific community over the past 20 years due to outstanding mechanical properties [28, 29], high specific surface area and interesting optical characteristics [30]. Great attention was paid to the isolation of nanofibers from cellulosic material and different methods are known to obtain this type of fibers such as acid hydrolysis [31], mechanical treatment [32-34] and bacterial nanocellulose [35].

Different kinds of surface functionalization were adopted to improve the adhesion between the hydrophilic surface of the cellulose and the hydrophobic behavior of PLA to improve the adhesion properties. Salajková et al. [36] proposed an interesting and environmentally friendly procedure to obtain hydrophobic cellulose nanocrystals with the aid of quaternary ammonium salts, the treated nanocellulose was easily dispersed in non-polar solvent. Coastal plants were used as a source of nanocellulose by Fortunati et al. [37]. In particular, nanocellulose obtained from the acid hydrolysis of Poseidonia oceanica plant wastes was added to neat PLA with the aid of a surfactant. It was evidenced the plasticizing effect of the surfactant leading the possibility of tuning the mechanical properties of the obtained film with different amount of functionalized and non-functionalized nanocellulose. Free radical melt grafting of maleic anhydride on the polymer chains of PLA is an efficient and an easy way to improve the compatibility of polymer and different kind of natural fiber from micro to nanometric scale and it was adopted in several studies [38-45]. Amine functionalization of nanocellulose via silanization of the hydroxyl groups on the cellulose surface is an efficient way to improve the dispersion of nanofiller within the polymer and increase the mechanical properties of their relative composited as demonstrated by Lu et al. [46]. Ring opening polymerization of L-lactide was employed to functionalize cellulose nanocrystals by Lizundia et al. [47] and the obtained functionalized nanocrystals were melt-mixed with neat PLA; the extruded biocomposite films exhibited a good interaction and adhesion between filler and the matrix, as demonstrated by the nucleation effect and by the improvement in the strain at break with respect to the neat PLA film. Nano-cellulose (also called cellulose nano-fibrils, $\mathrm{CNF}$ ) is a highly stable elongated nanostructure with diameter of few $\mathrm{nm}$ and length in the $100 \mathrm{~nm}$ range showing high optical transparency and excellent mechanical properties [48]. Their use as filler to improve 
the gas barrier properties of the PLA matrix has been recently proposed in studies revealing that dense CNF films formed by self-assembled CNF exhibit high optical transparency and gas- impermeable properties $[49,50]$.

In this research, PLA composites containing functionalized $\mathrm{CNF}$ were produced by solvent mixing in chloroform at various filler content ranging from 1 to $20 \mathrm{wt} \%$. Nanocellulose was preliminary functionalized via esterification with hydrophobic lauryl chains, in order to favor the dispersion of CNF in non-polar solvent and thus limit its aggregation process in the PLA matrix. The microstructure was observed by electron microscopy, the thermal response was investigated by differential scanning calorimetry, while mechanical properties were determined by quasi-static tensile tests, dynamic mechanical thermal analysis and creep tests. Gas barriers properties were determined by using deuterium, nitrogen and carbon dioxide as probing gases. The obtained information complement the existing literature on PLA films with cellulose nanoparticle reporting on their mechanical and physical properties [51-56].

\section{Experimental}

\subsection{Nanocomposite preparation}

Poly(lactic acid) (PLA 4032D) with a density of $1.24 \mathrm{~g} / \mathrm{cm}^{3}$ and a melting point of $160^{\circ} \mathrm{C}$ was purchased from Nature Works LLC. High purity cellulose was obtained from commercial bags of hydrophilic cotton wool ( $99 \%$ of cellulose), in conformity with Official Pharmacopoeia. Tetrahydrofuran (10999-9), Toluene (108-88-3), Pyridine (110-86-1) and Ethanol (64-17-5) were used for the preparation and modification of the nanocellulose. Chloroform (6766-3) was used in the preparation of the composite material. All the chemicals were purchased from Sigma Aldrich (Saint Louis, Missouri, USA) and used without any further purification.

\section{Synthesis of nanocellulose}

In a $250 \mathrm{ml}$ flask containing $5 \mathrm{~g}$ of cellulose fibers from cotton wool, $150 \mathrm{ml}$ of $40 \%$ sulfuric acid were added and the mixture stirred 1 hour at $50^{\circ} \mathrm{C}$. The resulting solid was neutralized with a sodium carbonate solution and further washed with tetrahydrofuran and finally dried under vacuum. Nanofibers lower than $100 \mathrm{~nm}$ in diameter with a length of $2.45 \pm 0.96 \mu \mathrm{m}$, according to SEM analyses, were obtained.

ATR-FTIR ( $v$ in $\left.\mathrm{cm}^{-1}\right): 3350$ (stretch. OH); 2902 (stretch. CH); 1430 (bend. CH); 1160 (bend. C-O-C); 1058 (stretch. $\mathrm{C}-\mathrm{O}-\mathrm{C} / \mathrm{C}-\mathrm{O}-\mathrm{H}$ ); 897 (stretch. $\mathrm{C}-\mathrm{O}-\mathrm{C}$ ).

\section{Synthesis of lauryl functionalized nanocellulose (LNC)}

In a $100 \mathrm{ml}$ flask, nanocellulose fibers $(1 \mathrm{~g})$ and lauryl chloride $(11.5 \mathrm{ml})$ were suspended in toluene $(15 \mathrm{ml})$ and pyridine $(4.1 \mathrm{ml})$. The mixture was heated at $80^{\circ} \mathrm{C}$ for 5 hours and precipitated by the addition of ethanol $(400 \mathrm{ml})$. The product was further washed with ethanol in order to completely eliminate the pyridine and the excess of lauryl chloride. The obtained lauryl- functionalized CNF (named as LNC) was dried under vacuum.

ATR-FTIR ( $v$ in $\left.\mathrm{cm}^{-1}\right)$ : 2902 (stretch. $\left.\mathrm{CH}\right) ; 2857$ (stretch. $\mathrm{CH}$ ); 1750 (stretch. COester); 1430 (bend. $\mathrm{CH}$ ); 1160 (bend. $\mathrm{C}-\mathrm{O}-\mathrm{C}$ ); 1146 (bend. $\mathrm{C}-\mathrm{O}-\mathrm{C}_{\text {ester }}$ ); 1058 (stretch. $\mathrm{C}-\mathrm{O}-\mathrm{C} / \mathrm{C}-\mathrm{O}-\mathrm{H}$ ); 897 (stretch. $\mathrm{C}-\mathrm{O}-\mathrm{C}$ ).

\section{Preparation of nanocomposites}

Biopolymer nanocomposites were prepared by solution mixing and casting. PLA was homogeneously dissolved in chloroform ( $1 \mathrm{~g} \mathrm{PLA} / 25 \mathrm{ml} \mathrm{CHCl}_{3}$ ) under magnetic stirring at $40^{\circ} \mathrm{C}$. Functionalized nanocellulose was dispersed in chloroform $(0.1 \mathrm{~g} \mathrm{LNC} /$ $10 \mathrm{ml} \mathrm{CHCl}_{3}$ ) and sonicated by a Hielscher $400 \mathrm{~S}$ ultra-sonicator equipped with a sonotrode with $1 \mathrm{~mm}$ diameter at a power of $200 \mathrm{~W}$ for at least 10 minutes in an ice bath. PLA and LNC solutions were then mixed with a magnetic stirrer for 3 hours to obtain solutions with different LNC filler content in the range $1-20 \mathrm{wt} \%$. Bubbles were removed in an ultrasonic bath for 5 minutes. These solutions were casted in a Petri dish with diameter of $150 \mathrm{~mm}$ and the solvent was let to evaporate first at room temperature
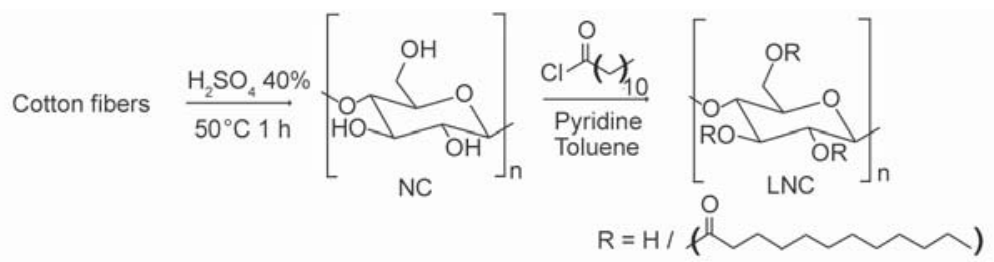

Figure. 1. Synthesis of lauryl functionalized nanocellulose (LNC). 
for 24 hours and then for 4 hours in a ventilated oven at $40^{\circ} \mathrm{C}$. Film of about 50 micron were obtained and stored in desiccator with silica gel until the use.

\subsection{Microstructure}

The microstructural characterization of the prepared nanocomposite samples was carried out by a JEOL high resolution field emission scanning electron microscope FE-SEM (Tokyo, Japan) at an accelerating voltage of $5 \mathrm{kV}$, analyzing the cryo fractured crosssection after the deposition of a conductive gold coating.

\subsection{Thermal analyses and spectroscopy}

Differential scanning calorimetry (DSC) measurements were performed with a Mettler DSC 30 calorimeter (Schwarzenbach, Switzerland). Samples of $10 \mathrm{mg}$ were analyzed under a nitrogen flow of $150 \mathrm{ml} / \mathrm{min}$, from 0 to $220^{\circ} \mathrm{C}$, heating and cooling runs were performed at $10^{\circ} \mathrm{C} / \mathrm{min}$. The glass transition temperature $\left(T_{\mathrm{g}}\right)$ was evaluated as the inflection point of DSC thermograms while the melting temperature $\left(T_{\mathrm{m}}\right)$ was estimated in correspondence of the endothermic peak. The enthalpy values were evaluated as the integral of their corresponding peaks: area under exothermic peak to estimate enthalpy of crystallization, and area under endothermic peak to estimate enthalpy of melting. The crystallinity content $\left(\Delta X_{\mathrm{c}}\right)$ of PLA was calculated using the Equation (1):

$$
\Delta X_{\mathrm{c}}=\frac{\Delta H_{\mathrm{m}}-\Delta H_{\mathrm{C}}}{\Delta H_{\mathrm{r}}\left(1-x_{\mathrm{LNC}}\right)}
$$

where, $\Delta H_{\mathrm{m}}$ is the enthalpy of melting, $\Delta H_{\mathrm{C}}$ is the enthalpy of crystallization, $\Delta H_{\mathrm{r}}$ is the reference enthalpy of fusion of $100 \%$ crystalline PLLA (taken equal to $93.6 \mathrm{~J} / \mathrm{g}$ [57]), and $x_{\mathrm{LNC}}$ is the $\mathrm{LNC}$ fraction. The maximum crystallizability Max $\Delta X_{\mathrm{c}}$ is calculated according to Equation (2):

$$
\operatorname{Max} \Delta X_{\mathrm{c}}=\frac{\Delta H_{\mathrm{m}}}{\Delta H_{\mathrm{r}}\left(1-x_{\mathrm{LNC}}\right)}
$$

FT-IR analysis of the PLA/LNC T films was performed by Fourier-Transform Infrared (FT-IR) spectroscopy using a from Perkin-Elmer instrument Spectrum One (Waltham, MA, USA) in the wavenumber range from 4000 to $650 \mathrm{~cm}^{-1}$ with resolution of $4 \mathrm{~cm}^{-1}$ to have information on the chemical interaction between PLA and the functionalized nano-cellulose filler.
The optical transparency of the cast films was measured by a Jasco 570 UV-VIS-NIR (Easton, MD, USA) spectrophotometer, determining the energy absorbed in a spectral wavelength range from 250 to $800 \mathrm{~nm}$ at a scanning rate of $200 \mathrm{~nm} / \mathrm{min}$. The relative transmittance $(T[\%])$ of neat PLA and LNC nanocomposites was evaluated by using film specimen of about 50 micron over the all wavelength range. The absorption $A$ at a selected wavelength was determined on the basis of Lambert-Beer's law [58] (Equation (3)):

$$
A_{\text {film }}=\log \left(\frac{100}{T}\right)=\varepsilon_{\mathrm{c}} \cdot c \cdot l
$$

where $T$ is the experimental transmittance in percentage, $\varepsilon_{\mathrm{c}}$ is the absorption coefficient of the composites expressed in $\mathrm{c}^{-1} \cdot \mathrm{mm}^{-1}, c$ is the solute concentration (in this case $c=1$ ), and $l$ is the optical path (film thickness).

\subsection{Mechanical properties}

Dynamical mechanical thermal analysis (DMTA) measurements were performed by using a DMA Q800 device from TA Instruments (Waters LLC, New Castle, DE, USA) under tensile configuration. Rectangular samples of $(20 \times 5 \mathrm{~mm})$, were tested in a temperature range between -10 and $110^{\circ} \mathrm{C}$ at a heating rate of $3{ }^{\circ} \mathrm{C} / \mathrm{min}$ and subjected to an oscillating strain of $0.05 \%$ at $1 \mathrm{~Hz}$ frequency to determine the temperature dependence of the storage modulus $\left(E^{\prime}\right)$, loss modulus $\left(E^{\prime \prime}\right)$ and loss tangent $(\tan \delta)$.

Quasi-static tensile tests were performed by using the DMA Q800 (TA Instruments, Waters LLC, New Castle, DE, USA) device in tensile mode at room temperature by using rectangular specimens of $20 \times 5 \mathrm{~mm}$ with a crosshead speed of $100 \mu \mathrm{m} / \mathrm{min}$ to investigate the mechanical properties, specifically the elastic modulus $(E)$, the strength $\left(\sigma_{\mathrm{B}}\right)$ and the strain at break $\left(\varepsilon_{\mathrm{B}}\right)$. At least three specimens for each sample were tested.

The geometrical stability of the films was investigated by measuring the creep compliance of the nanocomposite samples. Creep tests were carried out by using the same DMA Q800 device. The temperature was kept constant at $30^{\circ} \mathrm{C}$ under a constant tensile stress of $1 \mathrm{MPa}$ and the displacement was recorded for 3600 seconds. The creep compliance $C(t)$ was calculated as the ratio between the time dependent deformation $\varepsilon(t)$ and the applied stress. 


\subsection{Gas transport properties}

Gas transport tests were performed by using a home - made apparatus and high purity dry deuterium $\left(\mathrm{D}_{2}\right)$, nitrogen $\left(\mathrm{N}_{2}\right)$, and carbon dioxide $\left(\mathrm{CO}_{2}\right)$ as test gases which have different kinetic diameter (2.89, 3.30 and $3.64 \AA$, respectively) and critical temperature (38.2, 126.2 and $304.2 \mathrm{~K}$, respectively). Experiments were carried out at a constant temperature of $310 \pm 1 \mathrm{~K}$ by gas phase permeation technique using planar film specimens shaped in form of thin disc with diameter $d=13.5 \pm 0.1 \mathrm{~mm}$ and thickness $L$ of about $50 \mu \mathrm{m}$, which was measured before the transport test by using a micrometer caliper (thickness indetermination $\sim 2 \%$ ).

Gas transport properties were examined by the following procedure, as previously described $[50,59]$. At time $t=0$ (trigger time of the experiment) one side of the planar film, called High Pressure Side (HPS), was exposed to the test gas kept at a fixed pressure $P_{\mathrm{HPS}}=40 \mathrm{kPa}$ (this pressure value was used to avoid mechanical damages of the sample during the experimental run). The other side, called low pressure side (LPS), faces an analysis chamber kept in high vacuum conditions. The gas permeation process consists of the transfer of gas molecules from the HPS of the sample to the analysis chamber through the film layers. Test gas molecules permeate through the film of surface area $A=1 / 4 \cdot \pi d^{2}$ at a rate $Q(t)=A \cdot j_{\exp }(t)$ where $j_{\exp }(t)$ is the permeation flux. In the analysis chamber the permeated molecules form a rarefied gas in thermal equilibrium with the chamber walls at temperature $T_{\text {cham }}$. The partial pressure $P_{\text {LPS }}^{\text {gas }}(t)$ of the test gas varies, as a function of time $t$, according to the following Equation (4) [60]:

$$
Q(t)=\frac{1}{R \cdot T_{\text {cham }}}\left[V \cdot \frac{\mathrm{d} P_{\mathrm{LPS}}^{\mathrm{gas}}(t)}{\mathrm{d} t}+S_{\mathrm{p}} \cdot P_{\mathrm{LPS}}^{\mathrm{gas}}(t)\right]
$$

where $R$ is the universal gas constant, $V$ is the volume of the analysis chamber and $S_{\mathrm{p}}$ the pumping speed of the vacuum system. In the present experimental approach, the permeation test is carried out under continuous pumping of the analysis chamber and the condition $S_{\mathrm{p}} / V \gg\left(1 / P_{\mathrm{LPS}}\right) \cdot\left(\mathrm{d} P_{\mathrm{LPS}}(t) / \mathrm{d} t\right)$ holds. Therefore, the permeation flux $j_{\exp }(t)$ is directly proportional to the instantaneous value of the partial pressure of the probe gas, as shown by Equation (5):

$$
Q(t)=A \cdot j_{\exp }(t)=S_{\mathrm{p}} \cdot P_{\mathrm{LPS}}^{\mathrm{gas}}(t)
$$

During the permeation experiments $P_{\mathrm{LPS}}^{\mathrm{gas}}(t)$ is measured, as a function of time, by a calibrated quadrupole mass spectrometer (QMS, QMG 420 Balzers) equipped with Secondary Electron Multiplier and grid- type ion source. The obtained $P_{\mathrm{LPS}}^{\mathrm{gas}}(t)$ data were converted into permeation flux curves $j_{\text {exp }}(t)$ through Equation (6):

$j_{\exp }(t)=\frac{1}{A} \cdot \frac{1}{R \cdot T_{\text {cham }}} \cdot S_{\mathrm{p}} \cdot P_{\mathrm{LPS}}^{\mathrm{gas}}(t)$

Tests were carried out using film samples of PLA and nanocomposites $1,3,6.5,8,10,12$ and $15 \mathrm{wt} \%$ of LNC.

Before gas transport tests, film samples were kept in high vacuum conditions inside the experimental apparatus for at least 12 hours [59].

\section{Results and discussions}

\subsection{Microstructure}

SEM micrographs of the cryogenically fractured cross-sections of nanocomposite film samples containing different amounts of lauryl-functionalized nano-cellulose are reported in Figure 2. Micrographs provide information on the morphology of the fractured surface and illustrate the filler dispersion and aggregation process as a function of LNC content. The fracture surface of the pure PLA sample, see Figure 2a, shows a smooth and uniform surface without specific features; the inset of this figure shows the sample cross-section at lower magnification (the marker here indicates $10 \mu \mathrm{m}$ ) which demonstrates that the present preparation procedure permits to obtain biopolymer nanocomposites films with high degree of thickness uniformity.

Figure $2 b$ shows the cross-section of the sample with $3 \mathrm{wt} \%$ of LNC. This micrograph evidences that the fracture of the PLA matrix becomes more brittle when LNC is dispersed. In fact, the fractured surface appears corrugated with cavities of non-uniform size and shape. Figure $2 \mathrm{c}$ shows, at higher magnification, the wall of cavities revealing the presence of dispersed filler nanoparticles, see arrows. Moreover, the fracture surface evidences various elongated structures with nanocellulose at the tip of the plastic nanofibrils. Similar morphological features have been also observed in nanocomposites with $1 \mathrm{wt} \%$ of filler content.

Figure $2 \mathrm{~d}$ shows a SEM micrograph of the nanocomposite with $6.5 \mathrm{wt} \%$ of LNC. It can be observed that 


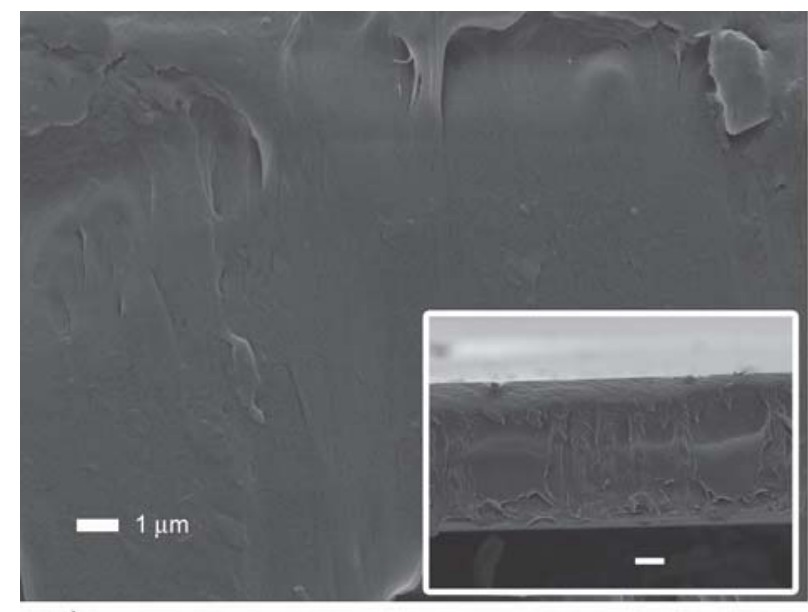

a)

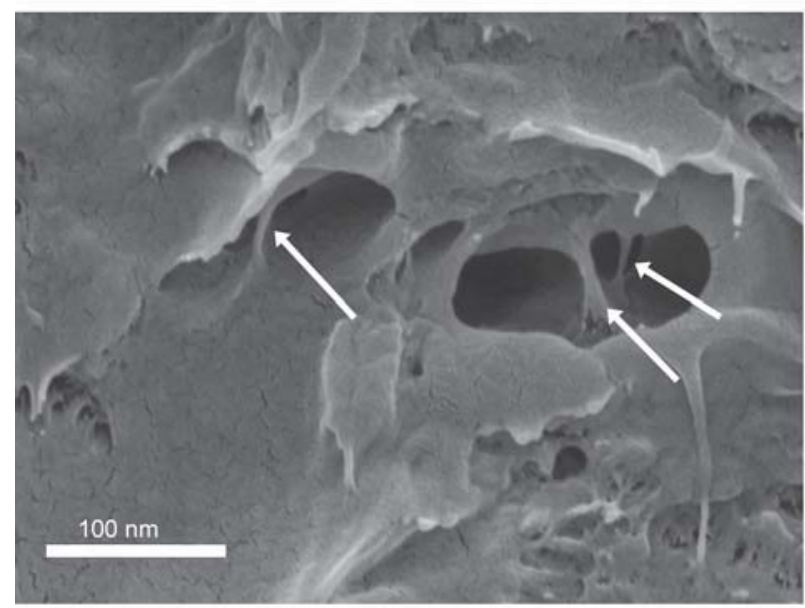

c)

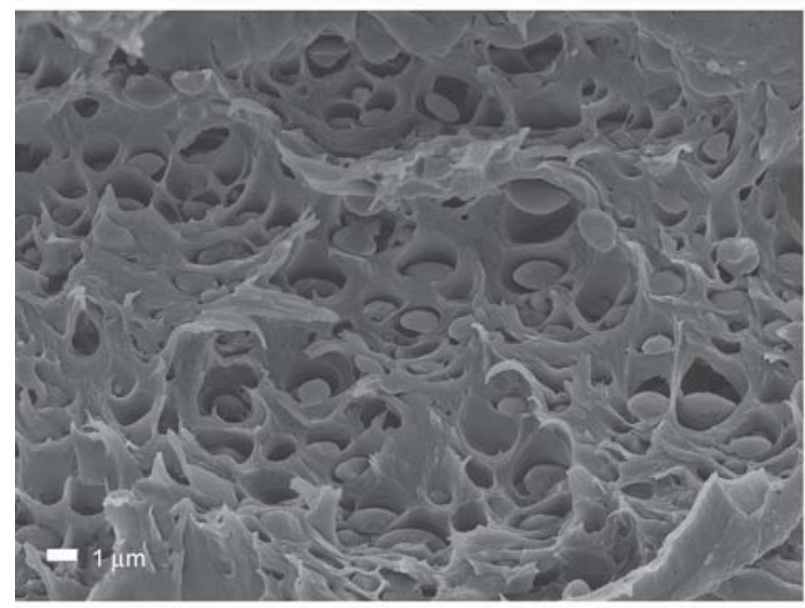

e)

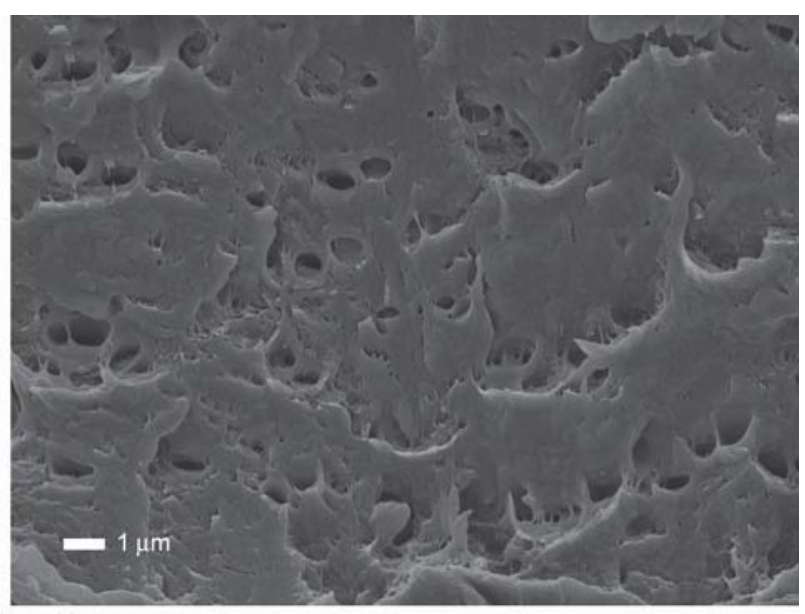

b)

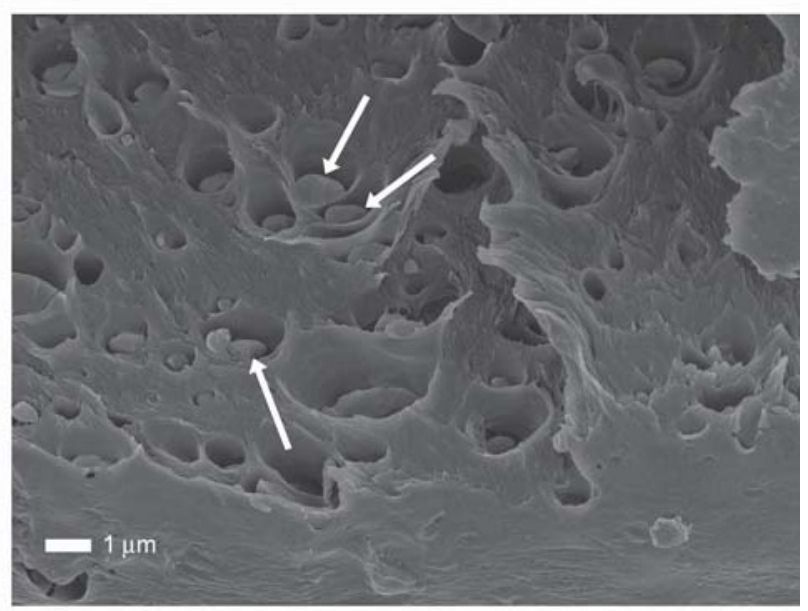

d)

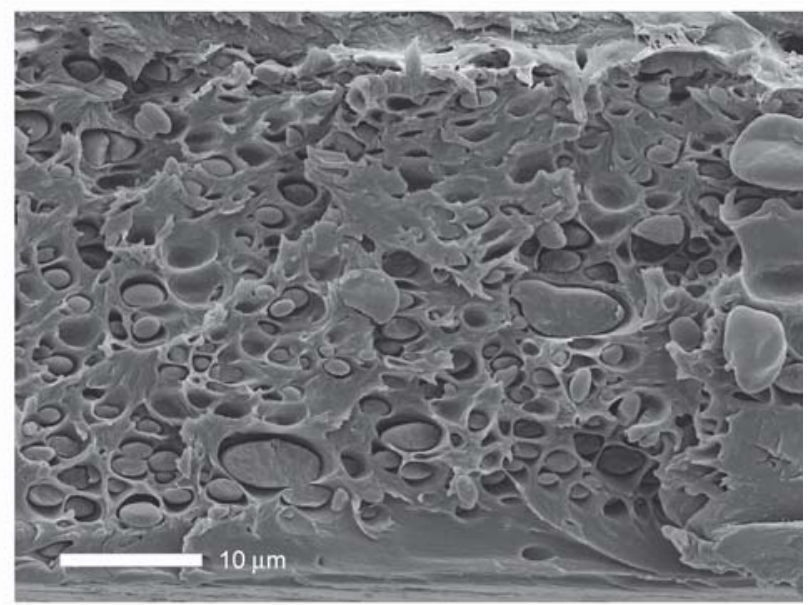

f)

Figure 2. Cross section SEM micrographs of (a) pure PLA sample (at lower magnification in the inset, marker: $10 \mu \mathrm{m}$ ); (b) PLA $+3 \mathrm{wt} \%$ LNC nanocomposite; (c) cavity walls in PLA $+3 \mathrm{wt} \% \mathrm{LNC}$ nanocomposite (high magnification); (d) PLA + $6.5 \mathrm{wt} \%$ LNC nanocomposite, (e) PLA + $10 \mathrm{wt} \%$ LNC nanocomposite; (f) PLA + $20 \mathrm{wt} \% \mathrm{LNC}$ nanocomposite.

LNC particles precipitate forming domains with irregular shape as indicated by the arrows and diameter of $0.8 \pm 0.1 \mu \mathrm{m}$. Cavities in the PLA matrix have non-uniform size and shape and are similar to those observed in Figure 2b. Also, for this sample, some evidences of brittle fracture can be noticed. As the
LNC content increases, the precipitation process produces aggregates having an ovoidal shape and larger dimensions.

Figure 2e refers to the nanocomposite samples with $10 \mathrm{wt} \%$ of LNC. Nanocellulose aggregates with a size of $1.4 \pm 0.2 \mu \mathrm{m}$ and are hosted in cavities with 
similar size. When the filler content is increased, the size of the LNC aggregates also increases reaching a dimension of $4 \pm 2 \mu \mathrm{m}$, as documented in Figures $2 \mathrm{f}$ that refers to the nanocomposites with $20 \mathrm{wt} \%$ of LNC.

SEM micrographs taken at higher magnification inside cavities of samples where LNC aggregates form, show the presence of LNC nanoparticles evidencing that a fraction of the filler remains still dispersed.

\subsection{Thermal analysis and spectroscopy}

The thermal transitions of the neat PLA and of the nanocomposite samples were investigated using differential scanning calorimetry whose thermograms are reported in Figures 3. The glass transition temperature $T_{\mathrm{g}}$, the melting temperature $T_{\mathrm{m}}$ and the enthalpy of crystallization $\Delta H_{\mathrm{c}}$ and melting $\Delta H_{\mathrm{m}}$ as obtained from DSC data analysis, are summarized in Table 1.

The results indicate that up to a content of $10 \mathrm{wt} \%$ the introduction of LNC in the PLA matrix induces a slight increase of $T_{\mathrm{g}}$ from 57 to $58^{\circ} \mathrm{C}$, suggesting a certain interaction between the amorphous phase of PLA and the functionalized filler, similarly to the effect of nanocellulose nanocrystals [61] and fumed nanosilica [62]. On the other hand, a more significant variation $\left(62^{\circ} \mathrm{C}\right)$ is observed for nanocomposite at $20 \mathrm{wt} \%$ of LNC. In the same time, the crystallizability of the PLA matrix significantly decreases as the LNC content increases, as documented by large reduction of both crystallization and melting peak; moreover the position of crystallization peak, centered at $120^{\circ} \mathrm{C}$ in the case the pure PLA, is shifted at higher temperature (about $135^{\circ} \mathrm{C}$ ) after addition of LNC, evidencing certain limitations for PLA crystallization, due to the reduction of polymer chain mobility and the physical hindrance of LNC (the shape of peak is also modified).

On the other hand, different effects of various filler on PLA crystallization were reported in literature. For instance, commercial microfibrillated cellulose exhibited a relevant nucleating effect in PLA composite at 3-20\% [63]; according to Khoo et al. [61] cellulose nanocrystals (CNC) evidenced a slight reduction in crystallinity after addition at $1-2 \%$, and nucleation effect in PLA composite at 5\%; on the other hand, Spinella et al. [64] reported the same crystallizability of both PLA and its composites at $1-20 \%$ CNC after

Table 1. Glass transition temperature $\left(T_{\mathrm{g}}\right)$, melting temperature $\left(T_{\mathrm{m}}\right)$ crystallization $\left(\Delta H_{\mathrm{c}}\right)$ and melting $\left(\Delta H_{\mathrm{m}}\right)$ enthalpy of PLA and PLA-LNC nanocomposites, as obtained from DSC curves. Crystallinity content $\left(X_{\mathrm{c}}\right)$ and maximum attainable crystallinity $\left(\operatorname{Max} X_{\mathrm{c}}\right)$ are also reported.

\begin{tabular}{|c|c|c|c|c|c|c|c|}
\hline & $\begin{array}{c}T_{\mathrm{g}} \\
{\left[{ }^{\circ} \mathrm{C}\right]}\end{array}$ & $\begin{array}{c}T_{\mathbf{m}} \\
{\left[{ }^{\circ} \mathbf{C}\right]}\end{array}$ & $\begin{array}{c}\Delta H_{\mathrm{c}} \\
{\left[\mathbf{J} \cdot \mathrm{g}^{-1}\right]}\end{array}$ & $\begin{array}{c}\Delta H_{\mathrm{m}} \\
{\left[\mathbf{J} \cdot \mathrm{g}^{-1}\right]}\end{array}$ & $\begin{array}{c}T_{\text {g cooling }} \\
{\left[{ }^{\circ} \mathrm{C}\right]}\end{array}$ & $\begin{array}{l}X_{\mathrm{c}}^{*} \\
{[\%]}\end{array}$ & $\begin{array}{c}\operatorname{Max} X_{c}^{* * *} \\
{[\%]}\end{array}$ \\
\hline PLA & 57 & 165.9 & 24.4 & 27.0 & 53 & 2.8 & 28.8 \\
\hline PLA $+1 \mathrm{wt}^{2} \% \mathrm{LNC}$ & 58 & 166.7 & 7.5 & 10.4 & 54 & 3.1 & 11.2 \\
\hline PLA $+3 w t \%$ LNC & 58 & 166.5 & 6.0 & 7.7 & 56 & 1.9 & 8.5 \\
\hline $\mathrm{PLA}+5 \mathrm{wt} \% \mathrm{LNC}$ & 58 & 166.1 & 10.2 & 11.5 & 55 & 1.5 & 12.9 \\
\hline PLA + $10 \mathrm{wt} \% \mathrm{LNC}$ & 58 & 166.7 & 7.8 & 9.3 & 56 & 1.8 & 11.0 \\
\hline PLA + $20 \mathrm{wt} \% \mathrm{LNC}$ & 62 & 168.8 & 11.9 & 12.4 & 56 & 0.7 & 16.6 \\
\hline
\end{tabular}

*calculated according to Equation (1);

${ }^{* *}$ calculated from the melting peak according to Equation (2).
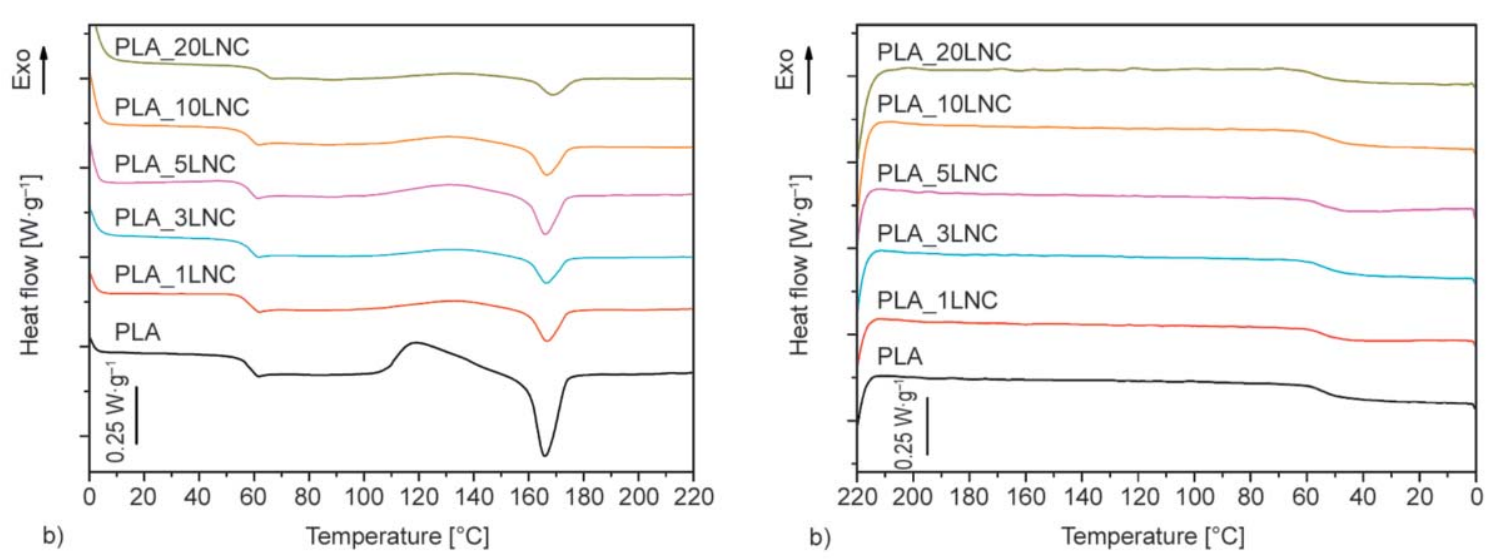

Figure 3. DSC heating (a) and cooling (b) curves of pure PLA and selected PLA-LNC nanocomposites. 
annealing at $130^{\circ} \mathrm{C}$. And in the case of PLA nanocomposite with fumed silica $2 \%$ no nucleation effect was observed [62].

Hence the functionalization of nanocellulose with a relatively long aliphatic chain appears as an inhibitor factor versus crystallization; however it should be noted that the presence of LNC marginally influences the quality of PLA crystals, being the melting temperature almost constant at about $166^{\circ} \mathrm{C}$ for the pure PLA and nanocomposite up to $10 \mathrm{wt} \%$ of LNC; only a slight increase at 168.8 for PLA nanocomposite with $20 \mathrm{wt} \%$ of LNC is detected.

In the cooling step none of the materials crystallizes, as shown in Figure 3b, and only a slight increase of $T_{\mathrm{g}}$ for LCN nanocomposites is observed (Table 1), confirming the lower mobility of polymer chains after introduction of functionalized filler.

All the produced film could be considered as amorphous materials, even if some minor differences could be distinguished. In particular, the crystallinity of the polymer in pure PLA and in nanocomposites with $1 \%$ of LNC is about $3 \%$, and much lower in nanocomposites containing filler in the range 3 $20 \mathrm{wt} \%$. Moreover, the maximum crystallizability could be calculated from the melting peak, Max $X_{\mathrm{c}}$ and it is clear that LNC exhibited values much lower than pure PLA, indicating that this nanofiller for specific reason reduce further crystallization of the matrix, where the role of lauryl chain appears.

Good transparency is a desirable property for most packaging applications. The optical response of specimens of about $50 \mu \mathrm{m}$ in thickness have been investigated by absorption measurements in the wavelength range $250-700 \mathrm{~nm}$. The obtained transmission spectra are shown in Figure 4. PLA with $1 \mathrm{wt} \%$ LNC shows light transmission values slightly higher than

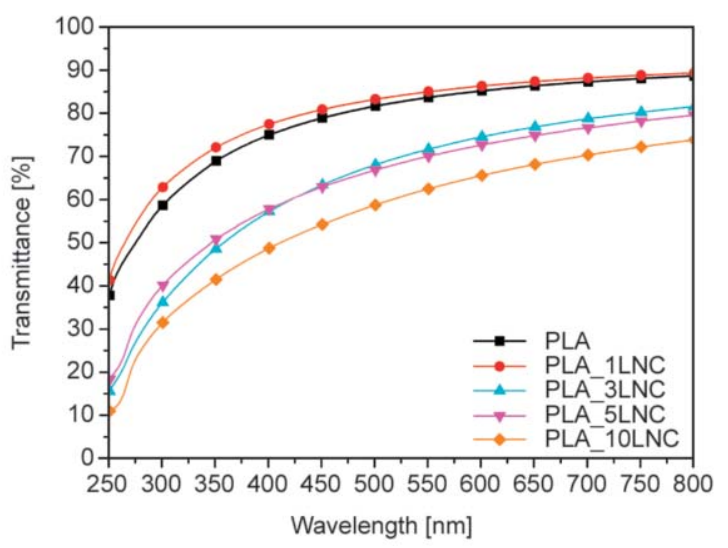

Figure 4. UV-VIS spectra of pure PLA and selected PLALNC nanocomposites. those of pure PLA sample. As the LNC amount increases, a progressive reduction of the film transparency can be observed due to the increase of aggregates in the matrix interacting with the visible light [63].

In order to determine the specific absorptivity of LNC $\left(E_{\mathrm{LNC}}\right)$, the normalized absorbance ( $\left.A_{\mathrm{PLA} / \mathrm{LNC}}\right)$ of materials referred to $1 \mathrm{~mm}$ was calculated according to Equation (7) [65]:

$A_{\mathrm{PLA} / \mathrm{LNC}}=\frac{A_{\mathrm{film}}}{d} \cdot 1000=A_{\mathrm{PLA}}+E_{\mathrm{LNC}} \cdot X_{\mathrm{LNC}} \cdot l_{\mathrm{R}}$

where $d$ is the film thickness expressed in micron, $A_{\text {film }}$ is the film absorption (from Equation (2)), $A_{\text {PLA }}$ is the absorption of PLA, $E_{\mathrm{LNC}}$ is absorptivity of $\mathrm{LNC}, X_{\mathrm{LNC} \text { is }}$ the concentration of LNC expressed in percentage by $\mathrm{wt} \%, l_{\mathrm{R}}$ is reference optical path (1 mm).

The values were calculated for two wavelengths in the visible spectra at 400 and $700 \mathrm{~nm}$, as reported in Table 2 after evaluating the correspondent absorption of PLA $A_{\text {PLA } 400}=2.56$ and $A_{\text {PLA } 700}=1.21$, respectively. The specific absorptivity $E_{\mathrm{LNC}}$ was determined directly for each single composition (except for $1 \% \mathrm{LNC}$ ) as reported in Table 2 . The values $E_{\mathrm{LNC}}$ at $400 \mathrm{~nm}$ (in the range $0.4-0.7$ ) were found higher than those at $700 \mathrm{~nm}(0.2-0.3)$, indicating a better transparency in the red zone of the spectrum. The higher the crystallinity of film, the higher the absorptivity coefficient, and the lower the transparency (an almost proportionality between adsorption and film crystallinity).

Moreover, due to the almost linear relationship between absorption and composition in the validity limit of Lambert-Beer law up to $10 \%$ of concentration, after linear fitting $E_{\mathrm{LNC} 400}=0.564+0.074$ $\left(R^{2}=0.94\right)$ and $E_{\mathrm{LNC} 700}=0.281+0.024\left(R^{2}=0.97\right)$ were calculated.

FT-IR analysis of the prepared PLA-based LNC nanocomposites was carried out to collect information on the composition and on the chemical interaction between the PLA matrix and the functionalized LNC filler particles.

The FT-IR spectra are shown in Figure 5, where the main peak at about $1750 \mathrm{~cm}^{-1}$ due to the stretching of the carbonyl group is attributed to the ester group of PLA and to those attached to nano-cellulose deriving from the esterification with lauryl chloride $[47,64]$. More significant for composition is the zone 
Table 2. Absorbance of film $\left(A_{\text {film }}\right)$ and specific absorptivity $E_{\mathrm{LNC}}$ (referred to $1 \mathrm{~mm}$ ) of PLA-LNC nanocomposites determined at 400 and $700 \mathrm{~nm}$.

\begin{tabular}{|l|c|c|c|c|c|}
\hline & $\begin{array}{c}\text { Thickness, } \boldsymbol{L} \\
{[\boldsymbol{\mu m}]}\end{array}$ & $\boldsymbol{A}_{\text {film } \mathbf{4 0 0} \text { at } \mathbf{4 0 0} \mathbf{~ n m}}$ & $\boldsymbol{A}_{\text {film 700 }}$ at 700 $\mathbf{~ n m}$ & $\boldsymbol{E}_{\mathbf{L N C}}$ at 400 $\mathbf{~ n m}$ & $\boldsymbol{E}_{\mathbf{L N C}}$ at 700 $\mathbf{~ n m}$ \\
\hline PLA & 49 & 0.125 & 0.059 & - & - \\
\hline PLA+1 wt\% LNC & 48 & 0.111 & 0.055 & n.m. & n.m. \\
\hline PLA+3 wt\% LNC & 53 & 0.244 & 0.104 & 0.68 & 0.25 \\
\hline PLA+5 wt\% LNC & 52 & 0.238 & 0.116 & 0.40 & 0.21 \\
\hline PLA+10 wt\% LNC & 39 & 0.313 & 0.153 & 0.55 & 0.28 \\
\hline
\end{tabular}

n.m. - not measurable

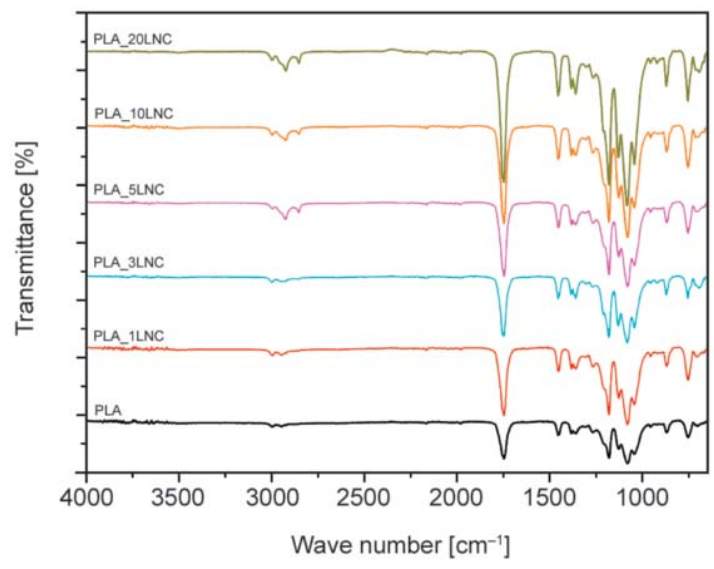

Figure 5. FT-IR spectra for pure PLA and selected PLALNC nanocomposites.

of aliphatic $\mathrm{C}-\mathrm{H}$ stretching. In the pure PLA matrix is possible to identify peaks at 2996 and $2947 \mathrm{~cm}^{-1}$ associated with the antisymmetric and symmetric stretching vibrations of $\mathrm{CH}_{3}$ of saturated hydrocarbons. As the LNC content increases, the peaks at 2924 and $2855 \mathrm{~cm}^{-1}$ due to the stretching vibration of methylene group $\left(-\mathrm{CH}_{2}-\right)$ in the lauryl chain [38]. The lack of any absorption peak near $3600 \mathrm{~cm}^{-1}$ indicates a good degree of substitution of $\mathrm{OH}$ groups on the surface of the functionalized nano-cellulose and the dry grade of the film.

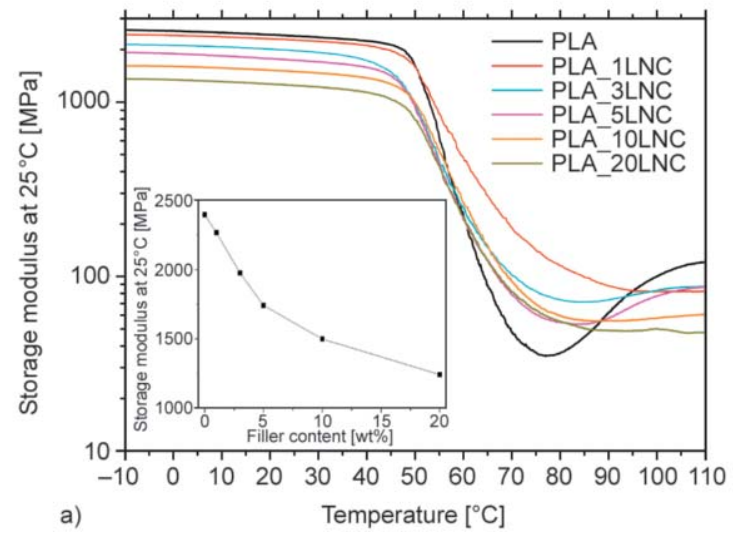

\subsection{Mechanical properties}

The effect of the incorporation of the functionalized nano-cellulose on the dynamic-mechanical properties of PLA film are presented in Figure 6.

A progressive decrease in the storage modulus $\left(E^{\prime}\right)$ with the increasing amount of nanocellulose is observed. This behavior is directly dependent on the functionalizing chains that could be interpreted according to Kelnar et al. [66], as a kind of soft interface between nanocellulose and the glassy PLA matrix. $E^{\prime}$ at $25^{\circ} \mathrm{C}$ linearly decreases with a double slope tendency from $2405 \mathrm{MPa}$ for the neat polymer to 1750 and to $1242 \mathrm{MPa}$ for the nanocomposite containing 5 and $20 \mathrm{wt} \%$ of LNC, respectively. This trend reverses above the glass transition temperature where the neat PLA presents the lowest value of $E^{\prime}$ among the tested composites. The increase of LNC content has only a marginal effect on the $\tan \delta$ peak temperature. Concurrently, the $\tan \delta$ peak value of PLA $(0.29)$ decreases with the introduction of LNC which is reducing the damping behavior, because the filler decreases the mobility of the rubbery phase that is forming during the transition. The minimum value of damping peak (0.21) is shown in Figure $6 \mathrm{~b}$ from the composite with $1 \%$ of LCN that could be attributed

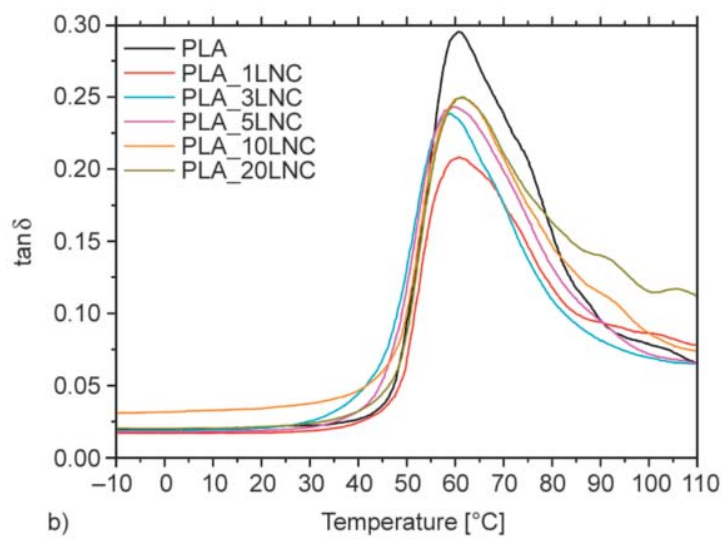

Figure 6. Effect of LCN filler on (a) storage modulus and (b) $\tan \delta$ curves for selected PLA and PLA-LNC nanocomposite. Insert in Figure 6 a reports the storage modulus values at $25^{\circ} \mathrm{C}$ as a function of the filler content. 
to the relative higher crystallinity (Table 2 ). On the other hand, the trend of storage modulus above $T_{\mathrm{g}}$ is not linear, due to a combined effect of PLA matrix and LNC filler. In particular at $70^{\circ} \mathrm{C}$, all nanocomposites exhibited a higher modulus than PLA matrix (Figure 6a). The maximum value for PLA nanocomposite with $1 \mathrm{wt} \% \mathrm{LNC}(190 \mathrm{MPa})$ is influenced by a combined effect of the higher crystallinity (about $3 \%$ ) and the stiffening effect of LNC in rubbery PLA. At higher filler content between 3 and 20\%, the main role is played by $\mathrm{LNC}$, and it determines a storage modulus in the range $80-100 \mathrm{MPa}$. Similar effects of the filler on PLA above $T_{\mathrm{g}}$ have been also documented by Spinella et al. [64] and Suyanegara et al. [67] for cellulose nanocrystals and microfibrillar cellulose, respectively.

Biopolymer nanocomposites were analyzed to evaluate elastic modulus, ultimate tensile strength (UTS) and strain at break of PLA by tensile test; results are reported in Table 3. As the amount of lauryl functionalized nano-cellulose increases inside, the stiffness of the tested films also decreases, in accordance with the DMA data regarding the decrease of the storage modulus at room temperature. This behavior could be related to the low stiffness of the short aliphatic chains attached to the surface of the cellulose leading to a plasticizing effect. The decrease of stiffness upon the introduction of functionalized nanocellulose in PLA matrix is reported in literature

Table 3. Mechanical properties of PLA-LNC nanocomposites with different LNC filler content.

\begin{tabular}{|l|c|c|c|}
\hline & $\begin{array}{c}\text { Elastic } \\
\text { modulus } \\
{[\text { MPa] }}\end{array}$ & $\begin{array}{c}\text { UTS } \\
{[\text { MPa] }]}\end{array}$ & $\begin{array}{c}\text { Strain at } \\
\text { break } \\
{[\%]}\end{array}$ \\
\hline PLA & $1770 \pm 100$ & $40 \pm 1$ & $70 \pm 20$ \\
\hline PLA+1 $\mathrm{wt} \%$ LNC & $1740 \pm 140$ & $45 \pm 3$ & $30 \pm 10$ \\
\hline PLA+3 $\mathrm{wt} \%$ LNC & $1130 \pm 100$ & $26 \pm 1$ & $>230$ \\
\hline PLA+5 $\mathrm{wt} \%$ LNC & $1060 \pm 60$ & $27 \pm 4$ & $>130$ \\
\hline PLA+10 $\mathrm{wt} \%$ LNC & $1010 \pm 60$ & $21 \pm 2$ & $35 \pm 10$ \\
\hline PLA+20 $\mathrm{wt} \%$ LNC & $950 \pm 30$ & $18 \pm 2$ & $30 \pm 10$ \\
\hline
\end{tabular}

also for other compatibilizer such as polyethylene glycol [38], acetyltributyl citrate [38, 63] and surfactants [37].

Films with 3 and $5 \mathrm{wt} \%$ of LNC exhibited the greatest strain at break, indicating a strong interfacial adhesion between the filler and the PLA matrix. This effect is confirmed also from SEM observation, see Figures $2 b$ and $2 d$ where it is possible to appreciate a large amount of plastic deformation on the surface of the fracture. For higher amount of nano-cellulose, the presence of aggregates inside the matrix weaken the films leading to lower values of maximum stress (UTS) and strain at break.

Creep measurements are of great practical importance in any application where polymeric materials must sustain loads for long periods of time and maintain their dimensional stability. The results are summarized in Table 4. The total creep compliance in isothermal tensile creep in the linear viscoelastic region, $C(t)$, is generally viewed as consisting of two components, $C_{\mathrm{el}}$ that represents the elastic response that it is instantaneous and reversible and $C_{\mathrm{ve}}(t)$ that denotes the time-dependent viscoelastic answer, if no plastic deformation is produced during the creep test (see Equation (8)) [68]:

$$
C(t)=C_{\mathrm{el}}+C_{\mathrm{ve}}(t)
$$

Creep resistance is worsened by the introduction of the nanofiller: in fact, creep compliance value measured at 3600 seconds rises from $0.9 \mathrm{GPa}^{-1}$ of the pure PLA film up to $2.56 \mathrm{GPa}^{-1}$ of the sample with $20 \mathrm{wt} \%$ of LNC. It is evident that the addition of lauryl functionalized nanocellulose influenced both $C_{\mathrm{el}}$ and $C_{\mathrm{ve}}(t)$, the short alkylic chains on the surface of nanocellulose enhance the molecular mobility of the composite, thus decreasing the creep stability. To model the viscoelastic creep response, Findley's model is frequently adopted to fit the experimental data. This model can be obtained by expanding the Kohlrausch-

Table 4. Results from creep compliance test and relative fitting values of the experimental data.

\begin{tabular}{|c|c|c|c|c|c|c|c|}
\hline & $\begin{array}{c}C_{3600 \mathrm{~s}} \\
{\left[\mathrm{GPa}^{-1}\right]}\end{array}$ & $\begin{array}{c}C_{\mathrm{el}} \\
{\left[\mathrm{GPa}^{-1}\right]}\end{array}$ & $\begin{array}{l}C_{\text {ve } 3600 \mathrm{~s}} \\
{\left[\mathrm{GPa}^{-1}\right]}\end{array}$ & $\begin{array}{c}C_{\mathrm{e}} \\
{\left[\mathrm{GPa}^{-1}\right]}\end{array}$ & $\begin{array}{c}k \\
{\left[\mathrm{GPa}^{-1} \cdot \mathbf{s}^{-\mathrm{n}}\right]}\end{array}$ & $n$ & $\operatorname{Adj} R^{2}$ \\
\hline PLA & 0.9 & 0.7 & 0.3 & $0.7 \pm 0.1$ & $4.1 \cdot 10^{-7} \pm 4 \cdot 10^{-7}$ & $1.6 \pm 0.1$ & 0.95 \\
\hline PLA $+1 w^{0} \%$ LNC & 1.2 & 0.6 & 0.7 & $0.5 \pm 0.1$ & $0.05 \pm 0.01$ & $0.3 \pm 0.1$ & 0.98 \\
\hline PLA $+3 w^{t} \%$ LNC & 2.4 & 0.8 & 1.6 & $0.6 \pm 0.5$ & $0.07 \pm 0.04$ & $0.4 \pm 0.1$ & 0.92 \\
\hline $\mathrm{PLA}+5 \mathrm{wt} \% \mathrm{LNC}$ & 2.5 & 1.2 & 1.4 & $1.0 \pm 0.1$ & $0.06 \pm 0.05$ & $0.4 \pm 0.1$ & 0.78 \\
\hline PLA $+10 \mathrm{wt} \% \mathrm{LNC}$ & 2.4 & 1.05 & 1.4 & $0.8 \pm 0.1$ & $0.08 \pm 0.06$ & $0.3 \pm 0.1$ & 0.85 \\
\hline PLA $+20 \mathrm{wt} \% \mathrm{LNC}$ & 2.5 & 1.7 & 0.8 & $1.6 \pm 0.1$ & $0.17 \pm 0.02$ & $0.2 \pm 0.1$ & 0.99 \\
\hline
\end{tabular}


Williams-Watts (KWW) model, generally described by a Weibull-like function as a series and ignoring all but the first term, as shown in Equation (9) [69]:

$C(t)=C_{\mathrm{e}}+k \cdot t^{\mathrm{n}}$

where $C_{\mathrm{e}}$ is the elastic instantaneous creep compliance, $k$ is a coefficient related to the magnitude of the underlying retardation process and $\mathrm{n}$ is an exponent tuning the time dependency of the creep process. The results from the fitting of experimental creep data are reported in Table 4 . The elevated $R$-square values show that the Findley equation can satisfactory represent the experimental data. The increase of the creep compliance due to the addition of functionalized nanocellulose was mostly associated to a slightly increase of the value $C_{\mathrm{e}}$ and a large intensification of the coefficient $k$, that tuned the time-dependent response to the applied stress. With the introduction of $1 \mathrm{wt} \%$ of LNC, $k$ is increased by 5 orders of magnitude, from $4.1,10^{-7}$ to $5.7 \cdot 10^{-2} \mathrm{GPa}^{-1} \cdot \mathrm{s}^{-\mathrm{n}}$ causing a transition to an elastic behavior to a viscous timedependent one.

\subsection{Gas transport properties}

In the present work the film specimens can be considered as membranes in which the lateral dimension $(d)$ is much greater than the thickness $(L)$ i.e $L \ll d$. Therefore, edge effects in the transport process through the planar samples can be neglected. This permits to analyze the transport process assuming a one-dimensional geometry of the membrane. According to the solution-diffusion models, gas transport through polymer membranes is controlled by three steps [70]. The first one is the absorption of penetrant molecules in the surface layers of the High Pressure Side (HPS) of the membrane. Gas concentration here immediately reaches the equilibrium value $c_{\mathrm{HPS}}$ which is given by the Henry law: $c_{\mathrm{HPS}}=$ $c(x=0, t)=\Pi \cdot P_{\mathrm{HPS}}$. In the previous relation, $x=0$ represents the coordinate of the HPS of the membrane along the flux direction $x$ while the $\Pi$ parameter is the equilibrium gas solubility in the membrane layers. The second step is the diffusion of the absorbed molecules from the HPS (at $x=0$ ) to the LPS (at $x=L$ ) with a concentration gradient. According to the first Fick law the gas flux $j(x, t)$ is given by the relation $j(x, t)=-D \cdot(\partial c(x, t)) / \partial x$ where $c(x, t)$ is the gas concentration at time $t$ in the membrane layers at depth $x$ below the HPS and $D$ is the gas diffusivity in the membrane layers. The last step is the desorption of the molecules from the LPS surface layers. The gas concentration in the LPS side of the membrane, $c_{\text {LPS }}$, is also given by the Henry law: $c_{\text {LPS }}=$ $c(x=L, t)=\Pi \cdot P_{\mathrm{LPS}}^{\mathrm{gas}}$.

The $c(x, t)$ quantity is obtained solving the Fick's second equation $(\partial c(x, t)) / \partial t=D \cdot\left(\partial^{2} c(x, t)\right) /\left(\partial x^{2}\right)$ with the previous boundary conditions in $x=0$ and $x=L$ and permits to calculate the gas permeation flux $j(t)$ by the relation $j(t)=j(x=L, t)=-D \cdot(\partial c(x=L, t)) / \partial x$. This diffusion problem admits for $j(t)$ the following analytical solution [71]:

$$
\begin{aligned}
j(t)= & \frac{D \Pi}{L}\left(P_{\mathrm{HPS}}-P_{\mathrm{LPS}}\right) . \\
& \cdot\left[1+2 \sum_{\mathrm{n}=1}^{\infty}(-1)^{\mathrm{n}} \exp \left(\frac{-D n^{2} \pi^{2} t}{L^{2}}\right)\right]
\end{aligned}
$$

Because $P_{\mathrm{LPS}}^{\text {gas }} \ll P_{\mathrm{HPS}}$ then the following approximation holds (Equation (10)):

$$
j(t)=\frac{D \Pi}{L} P_{\mathrm{HPS}}\left[1+2 \sum_{\mathrm{n}=1}^{\infty}(-1)^{\mathrm{n}} \exp \left(\frac{-D n^{2} \pi^{2} t}{L^{2}}\right)\right]
$$

Equation (6) indicates that the permeation process involves an initial transient condition where the $j(t)$ value increases with time $t$ which is followed by stationary transport conditions where the permeation flux $j(t)$ assumes the constant value: $j(t \rightarrow \infty)=J=$ $(D \cdot \Pi) / L \cdot P_{\mathrm{HPS}}=\phi / L \cdot P_{\mathrm{HPS}}$. The quantity $\phi=D \cdot \Pi$ is called the gas permeability. Equation (10) is used to fit the experimental $j_{\exp }(\mathrm{t})$ curves and obtain the $\phi$ and $D$ gas transport parameters.

In Figures 7 the $j_{\exp }(\mathrm{t})$ curves obtained with the $\mathrm{D}_{2}$, $\mathrm{N}_{2}$ and $\mathrm{CO}_{2}$ test gas, are respectively presented.

A summary of thickness of tested film and calculated permeability referred to 25 micron and expressed as [ $\mathrm{ml} 25 \mu \mathrm{m} / \mathrm{m}^{2} 24 \mathrm{~h}$ bar] is reported in Table 5 .

In each figure, kinetic curve of gas flux $j_{\exp }(t)$ pertinent to the reference PLA film is reported as solid symbols, and curves pertinent to representative nanocomposites are reported as open symbols. The best fit lines are calculated according to Equation (10). For clarity reasons, each curve reports sampled experimental data. Observing Figure 7 for the three test gases one can observe that: i) the gas transport process in the pure PLA sample as well as in all nanocomposites reaches stationary transport conditions in much shorter interval times using $\mathrm{D}_{2}$ (about $4-5 \mathrm{~s}$ ) 


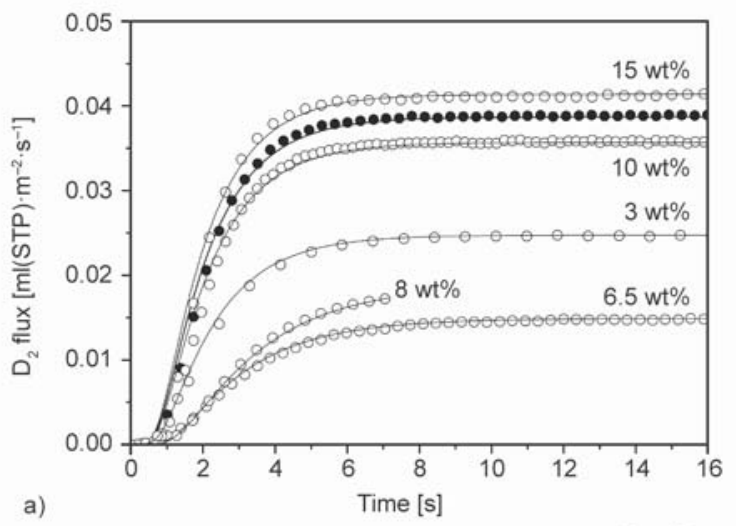

a)
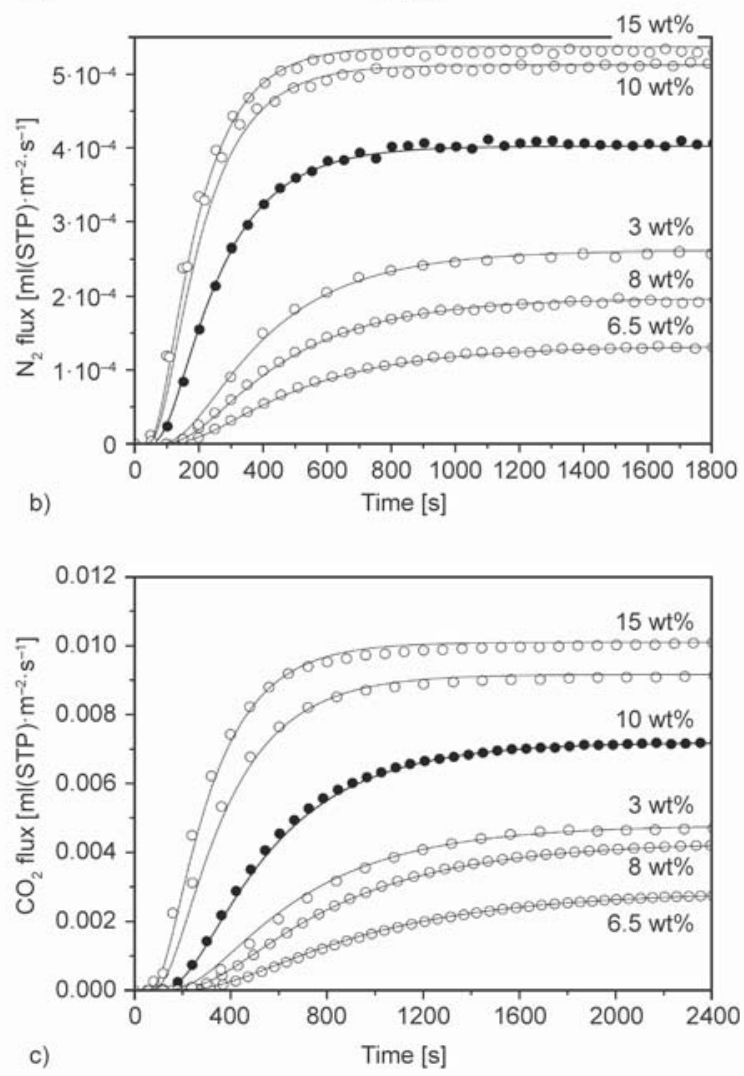

Figure 7. (a) $\mathrm{D}_{2}$, (b) $\mathrm{N}_{2}$, (c) $\mathrm{CO}_{2}$ permeation curves through film of PLA (solid symbols) and LNC nanocomposites at $T=310 \pm 2 \mathrm{~K}$ and $P_{\mathrm{HPS}}=40 \mathrm{kPa}$. Labels indicate the content of $\mathrm{LNC}$ (in the range $3-$ $15 \mathrm{wt} \%$ ) Lines: fits of data by Equation (10). than $\mathrm{CO}_{2}$ and $\mathrm{N}_{2}$ ( - about 500-700 s), as direct dependence on the molecule size; ii) $\mathrm{CO}_{2}$ and $\mathrm{N}_{2}$ present comparable duration of the transient regime, but different transport rates in stationary transport condition; and iii) with all gases the permeation flux $J$ in stationary transport conditions varies with the filler content with same trend. In fact, $J$ decreases increasing the filler content up to $6.5 \mathrm{wt} \%$ and then monotonically increases at higher filler content. The $j_{\text {exp }}(t)$ curves do not show major variations of the lasting of the transient transport conditions changing the filler content.

The values of the $D$ and $\phi$ gas transport parameters were obtained fitting of the experimental $j_{\exp }(t)$ curves by Equation (10), see continuous lines in Figures 7. Results are presented, as a function of the LNC filler content, in Figures 8 for gas permeability and diffusivity, respectively.

Figure $8 \mathrm{a}$ shows that the gas permeability of the pure PLA matrix decreases adding LNC filler particles and reaches its minimum value at $6.5 \mathrm{wt} \%$ : gas permeability is about a factor 3 lower than that of the pure PLA film samples. For filler contents higher than $6.5 \mathrm{wt} \%$, on the contrary, the nanocomposite permeability monotonically increases and reaches values comparable to that of pure PLA matrix at filler concentration close to $15 \mathrm{wt} \%$. At $20 \mathrm{wt} \%$ filler content the examined nanocomposite film exhibits higher permeability values than those of the pure PLA matrix. This trend is exhibited with all test gases indicating that adding the LNC filler particles the gas transport properties change in a not- gas selective way. The $\mathrm{D}_{2}$ gas permeability $\phi_{\mathrm{D}_{2}}$ in the pure PLA film exhibits a factor $\sim 5$ and factor $\sim 100$ higher than $\phi_{\mathrm{CO}_{2}}$ and $\phi_{\mathrm{N}_{2}}$, respectively. Similar values are observed when the additive content is close to $15 \mathrm{wt} \%$, whereas only minor changes are observed at $6.5 \mathrm{wt} \%$

Table 5. Thickness $(L)$ of tested film and calculated Permeability of PLA and various PLA-LNC nanocomposites referred to 25 micron at $310 \mathrm{~K}$.

\begin{tabular}{|c|c|c|c|c|}
\hline & $\begin{array}{c}L \\
{[\mu \mathrm{m}]}\end{array}$ & $\begin{array}{c}\mathrm{D}_{2} \text { permeability at } 310 \mathrm{~K} \\
{\left[\mathrm{ml} 25 \mu \mathrm{m} / \mathrm{m}^{2} 24 \mathrm{~h} \text { bar] }\right.}\end{array}$ & $\begin{array}{c}\mathrm{N}_{2} \text { permeability at } 310 \mathrm{~K} \\
{\left[\mathrm{ml} 25 \mu \mathrm{m} / \mathrm{m}^{2} 24 \mathrm{~h} \text { bar }\right]}\end{array}$ & $\begin{array}{c}\mathrm{CO}_{2} \text { permeability at } 310 \mathrm{~K} \\
{\left[\mathrm{ml} 25 \mu \mathrm{m} / \mathrm{m}^{2} 24 \mathrm{~h} \text { bar }\right]}\end{array}$ \\
\hline PLA & 49 & $1.86 \cdot 10^{4}$ & $2.01 \cdot 10^{2}$ & $3.45 \cdot 10^{3}$ \\
\hline PLA $+1 \mathrm{wt} \% \mathrm{LNC}$ & 48 & $1.78 \cdot 10^{4}$ & $1.90 \cdot 10^{2}$ & $3.15 \cdot 10^{3}$ \\
\hline PLA + $3 \mathrm{wt}^{2} \% \mathrm{LNC}$ & 53 & $1.14 \cdot 10^{4}$ & $1.38 \cdot 10^{2}$ & $2.54 \cdot 10^{3}$ \\
\hline PLA $+6.5 \mathrm{wt} \% \mathrm{LNC}$ & 52 & $7.25 \cdot 10^{3}$ & $6.83 \cdot 10^{1}$ & $1.45 \cdot 10^{3}$ \\
\hline $\mathrm{PLA}+8 \mathrm{wt} \% \mathrm{LNC}$ & 55 & $9.45 \cdot 10^{3}$ & $1.05 \cdot 10^{2}$ & $2.33 \cdot 10^{3}$ \\
\hline PLA + $10 \mathrm{wt} \% \mathrm{LNC}$ & 39 & $1.39 \cdot 10^{4}$ & $2.00 \cdot 10^{2}$ & $3.39 \cdot 10^{3}$ \\
\hline PLA + $12 \mathrm{wt} \%$ LNC & 57 & $1.40 \cdot 10^{4}$ & $2.09 \cdot 10^{2}$ & $3.20 \cdot 10^{3}$ \\
\hline PLA + $15 \mathrm{wt} \%$ LNC & 50 & $2.07 \cdot 10^{4}$ & $2.65 \cdot 10^{2}$ & $5.05 \cdot 10^{3}$ \\
\hline
\end{tabular}



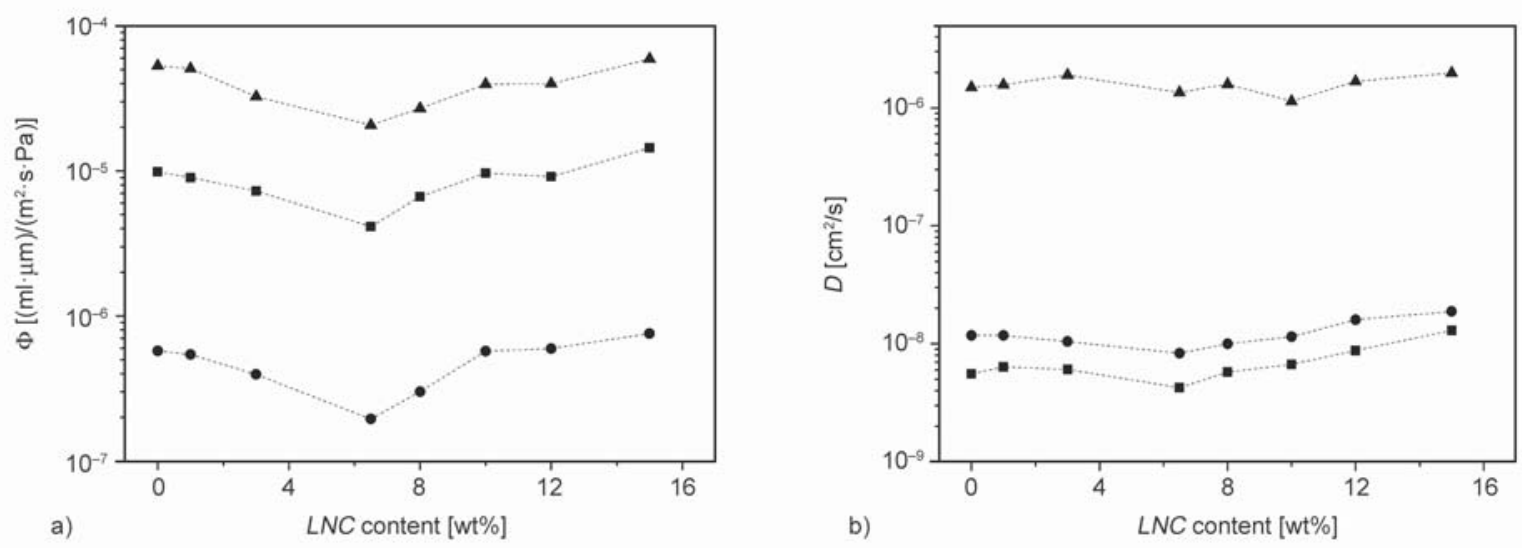

Figure 8. (a) Permeability values, (b) diffusivity at $T=310 \pm 1 \mathrm{~K}$ of the examined PLA-LNC nanocomposites as a function of the LNC filler content. (triangles: $\mathrm{D}_{2}$; squares: $\mathrm{CO}_{2}$; circles: $\mathrm{N}_{2}$ ).

filler content resulting in fact, $\phi_{\mathrm{D}_{2}} \sim 7 \phi_{\mathrm{CO}_{2}}$ and $\phi_{\mathrm{D}_{2}} \sim$ $140 \phi_{\mathrm{N}_{2}}$. It is interesting to note that a comparable minimum of permeability has been also found for oxygen in nanocomposite film with $5 \%$ of nanoclay in PLA/PBS blend [72].

The observed variation of the gas permeability values in dependence on the filler content, are not accompanied by similar variation of the gas diffusivity $D$, as shown by Figure 8b. These negligible variations of the penetrant diffusivity after the addition of nanocellulose could be related with the fact that LNC does not influence the chemical-physical properties of the polymer matrix as previously seen in DSC analysis where no relevant variation of the $T_{\mathrm{g}}$ and $T_{\mathrm{m}}$ values up to $10 \mathrm{wt} \%$ of filler content and only minor variations can be observed with filler content of $20 \mathrm{wt} \%$.

Observing the trend of permeability (Figure 8a) and the morphology of PLA-LNC nanocomposites shown in SEM micrographs (Figure 2), it is possible to conclude that the variation of the $\phi$ values with filler addition is depending on either the dispersion of LNC or/and their aggregation process in the PLA matrix. In fact: i) the gas permeability reduces adding filler as long as LNC is dispersed or forms small clusters with size in the sub- micrometer range; ii) the gas permeability increases when the addition of filler at LNC content higher than $6.5 \mathrm{wt} \%$ gives rise to $\mathrm{LNC}$ precipitation forming aggregates with size in the few micrometer range, in conformity to analogous literature interpretations [72].

Let us consider first permeability data pertinent to samples with filler content lower than $6.5 \mathrm{wt} \%$ : it is worthy to point out that the permeability reduction cannot be attributed to the reduction of the PLA specific volume, as complementary consequence of addition of the gas impermeable filler. In fact, taking into account that nano-cellulose has $1.5 \mathrm{~g} / \mathrm{cm}^{3}$ mass density [27] which is higher than that of the PLA matrix: $1.24 \mathrm{~g} / \mathrm{cm}^{3}$, when NCL content in the nanocomposite is $3 \mathrm{wt} \%(\sim 2.5 \mathrm{vol} \%)$ the PLA volumetric fraction is $\sim 97.5 \mathrm{vol} \%$ and the permeability reduction is assessed at $\sim 30 \%$, as evidenced in Figure 8a. On the other hand, a much higher permeability reduction of $\sim 70 \%$ has been observed at a filler content of $6.5 \mathrm{wt} \%$ that corresponds to PLA matrix fraction of $94.6 \mathrm{vol} \%$.

According to literature models describing the gas transport properties of Mixed Matrix Membranes (MMM), the gas transport properties of a polymer matrix are influenced by the addition of gas impermeable fillers by two mechanisms: i) the filler dispersion forces penetrant molecules to flow along longer diffusion paths than in the pure matrix: the apparent penetrant diffusivity, and thus the MMM permeability, is reduced depending both on the filler aspect ratio and on the filler content and ii) filler particles gives rise to variations of the physical-chemical properties of the polymer layers at the filler-matrix interface: these changes produce variations of the interface permeability values [72-78]. According to the experimental diffusivity values reported in Figure $8 \mathrm{~b}$, the decrease of gas permeability is caused by the process described in the latter point.

When chemical-physical variations of the polymer layers at the matrix-filler occur then the gas permeability of a $l_{\text {int }}$ thick interface regions around the filler particles is significantly different. Polymer chains here can be rigidified in comparison with the bulk polymer chains as consequence of the polymer-particle interfacial adhesion [75-78]. In this rigidified region the permeability $\phi_{\text {int }}$ is reduced with respect 
to that of the continuous polymeric phase $\phi_{\mathrm{PLA}}$ by a quantity $\beta$ called 'chain immobilization factor': $\phi_{\text {int }}=\phi_{\text {PLA }} \beta$. The filler may, on the contrary, increase the gas permeability of the filler-matrix interface layers $\phi_{\text {int }}$ because its presence disrupts the polymer chain packing and increase the free volume or because poor polymer-filler adhesion causes the formation of interface nano-cavities [75-78].

Literature models quantitatively describe the effects of the modified interface layers on the gas permeability of the pure matrix modelling the dispersed filler particles with $\phi_{\mathrm{d}}$ permeability and the surrounding modified polymer layer with $\phi_{\text {int }}$ permeability as a dispersed 'pseudo-phase' with effective permeability, as shown by Equation (11):

$\phi_{\text {eff }}=\phi_{\text {int }} \frac{\phi_{\mathrm{d}}+2 \phi_{\text {int }}-2 \varphi_{\mathrm{s}}\left(\phi_{\text {int }}-\phi_{\mathrm{d}}\right)}{\phi_{\mathrm{d}}+2 \phi_{\text {int }}+\varphi_{\mathrm{s}}\left(\phi_{\text {int }}-\phi_{\mathrm{d}}\right)}$

In this equation $\varphi_{\mathrm{s}}$ is the volume fraction of the filler in the 'pseudo-phase': the $\varphi_{\mathrm{s}}$ value depends both on the thickness of the interface layer as well as on the geometry of the filler particle.

When the filler particles can be described as long cylinders with length much longer than their diameter $2 r_{\mathrm{d}}$ then Equation (12) is valid:

$\varphi_{\mathrm{s}}=\frac{r_{d}^{2}}{\left(r_{d}+l_{\text {int }}\right)^{2}}$

and the effective permeability of the nanocomposite film $\phi_{\mathrm{NC}}$ can be the calculated by Equation (13):

$\phi_{\mathrm{NC}}=\phi_{\mathrm{PLA}} \frac{\phi_{\mathrm{eff}}+2 \phi_{\mathrm{M}}-2 \varphi_{\mathrm{pp}}\left(\phi_{\mathrm{M}}-\phi_{\mathrm{eff}}\right)}{\phi_{\mathrm{eff}}+2 \phi_{\mathrm{M}}+\varphi_{\mathrm{pp}}\left(\phi_{\mathrm{M}}-\phi_{\mathrm{eff}}\right)}$

In this equation, $\varphi_{\mathrm{pp}}$ is the volume fraction of the dispersed 'pseudo-phase' in the nanocomposite.

Experimental data in Figure 8a for filler content lower than $6.5 \mathrm{wt} \%$ can be reproduced assuming that in these nanocomposites polymer stiffening occurs: Figure $9 \mathrm{a}$ shows the calculated $\phi_{\mathrm{N} d} \phi_{\text {PLA }}$ values (solid symbols) and obtained from the experimental permeability data in Figure $8 \mathrm{a}$ as a function of the vol $\%$ filler content, $c_{\mathrm{LNC}}$. In the figure dotted lines are $\phi_{\mathrm{N} C} \phi_{\text {PLA }}$ values obtained for different $l_{\text {int }}$ values using Equation (11) and Equation (13) with $\beta=5$ (larger $\beta$ values give rise to undetectable changes in the fit lines). Looking at the figure, we conclude that for filler content lower than $6.5 \mathrm{wt} \%$ the observed permeability reduction is due to the formation of a strongly rigidified interface region with thickness $l_{\text {int }}=8-10 \mathrm{~nm}$ around filler particles. This value is about a factor 2 lower than in graphene-epoxy nanocomposites [79]. This stiffening effect could be attributed to the presence of the lauryl functional groups at the filler surface: the compatibility between the PLA matrix and the lauryl chains (functionalizing agents) reasonably reduces the free volume in the $10 \mathrm{~nm}$ thick interface region. Note that mechanical analysis evidence that nanocomposites with 3 and $5 \mathrm{wt} \%$ of LNC exhibited the greatest strain at break, indicating a strong interfacial adhesion between the filler and the PLA matrix also confirmed by SEM observation (Figures 2a-2d) which evidence a large amount of plastic deformation on the fractured crosssection surface.

Let us consider now data in Figure 8a indicating an increase of the gas permeability when the filler content in the nanocomposites is higher than $6.5 \mathrm{wt} \%$. Structural analysis evidence that in these samples LNC filler particles form spherical aggregates with size in the few micrometer range. Because regions around dispersed LNC particles have gas impermeable nature, the permeability increase in these samples can be attributed to the formation of regions around these spherical aggregates with permeability values higher than those of the PLA matrix. To quantitatively describe the experimental data, let us consider the nanocomposite with $6.5 \mathrm{wt} \%$ filler content as reference sample and examine the $\phi_{\mathrm{NC}} \phi_{\mathrm{NC}}^{\mathrm{PLA}}+6.5 \mathrm{wt} \%$ data which are reported in Figure 9b. In Figure 9b, the filler content (here expressed in vol\%) is represented as the LNC excess with respect to the PLA $+6.5 \mathrm{wt} \%$ reference sample (the values in 0 correspond to the ones at $6.5 \mathrm{wt} \%$ of Figure 9a) which implicitly assumes that all filler content above $6.5 \mathrm{wt} \%$ forms the observed aggregates. Dashed lines in Figure $9 \mathrm{~b}$ are data fitting of the $\phi_{\mathrm{NC}} \phi_{\mathrm{NC}}^{\mathrm{PLA}+6.5 \mathrm{wt} \%}$ data obtained assuming that the excess LNC filler particles form spherical LNC aggregates with $2 \mu \mathrm{m}$ diameter: the dispersed 'pseudo-phase' then consists of the filler aggregate and the surrounding spherical shell with $l_{\text {int }}$ thickness. Experimental $\phi_{\mathrm{NC}}\left\langle\phi_{\mathrm{NC}}^{\mathrm{PLA}}+6.5 \mathrm{wt} \%\right.$ data can be then reproduced assuming, for each test gas, interface shell thickness with size comparable with that of the LNC aggregates, see lint values in Figure $9 b$, and interface permeability values $\sim 100 \phi_{\text {PLA. }}$.

\section{Conclusions}

Biopolymer nanocomposites consisting of a poly(lactic acid) matrix (PLA) containing nano-cellulose filler 

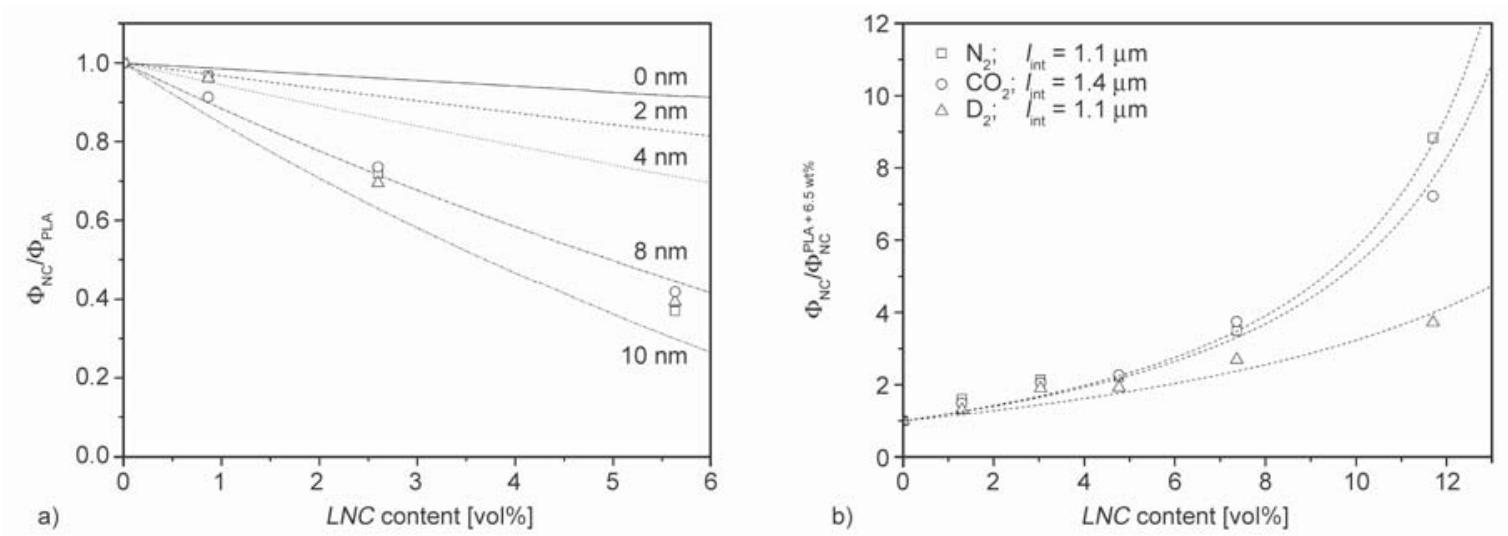

Figure 9. (a) $\phi_{\mathrm{NC}} / \phi_{\mathrm{PLA}}$ values of NCL nanocomposite samples as a function of the LNC volume content up to $6.5 \mathrm{wt} \%$. (triangles: $\mathrm{D}_{2}$; squares: $\mathrm{N}_{2}$; circles: $\mathrm{CO}_{2}$ ). Lines are obtained using Equation (11)-(13) with $\beta=5$ for different $l_{\text {int }}$ values between 0 and $10 \mathrm{~nm}$. (b) $\phi_{\mathrm{NC}} / \phi_{\mathrm{NC}}^{\mathrm{PLA}}+6.5 \mathrm{wt} \%$ values pertinent to the nanocomposite samples with filler content from 6.5 to $15 \mathrm{wt} \%$. The filler content is expressed in volumetric units, as excess with respect to the filler content of the PLA $+6.5 \mathrm{wt} \%$ reference sample. Lines are obtained using Equation (11)-(13) assuming interface shell thickness $\sim 1 \mu \mathrm{m}$ and effective interface gas permeability $\sim 100 \phi_{\text {PLA }}$.

particles (NC) functionalized by hydrophobic lauryl chain (LNC) via esterification reaction were prepared. The mechanical and gas transport properties of biopolymer with different filler concentration, were compared by dynamical mechanical thermal analysis and gas phase permeation technique, respectively. Results were correlated to structural information obtained by scanning electron microscopy, differential scanning calorimetry and Fourier transform infra-red analysis.

In particular, microscopy observations highlighted that till $6.5 \mathrm{wt} \%$, the functionalized nanocellulose was well dispersed in form of sub-micrometric cluster, whereas for higher concentration the filler started to precipitate in micrometric aggregates. The addition of nanocellulose particles, as well as their aggregation, did not significantly influence the structure of the PLA matrix as resulted from the almost constant glass transition and melting temperature. Only a minor decrease of crystallinity in nanocomposites was observed after DSC analysis. The storage modulus $E^{\prime}$ and stiffness of the nanocomposites decreased with the increasing of LNC fraction in the matrix, due to the introduction of short alkyl chains that could be considered as inner lubricating agents and inhibiting crystallization factors. These lauryl groups determined also an increase of the creep compliance and in particular of the time-dependent response of the material to constant load. Nanocomposites with 3 and $5 \mathrm{wt} \%$ of LNC showed the greatest strain at break, and a large amount of plastic deformation on the fractured cross-section surface had been evidenced, suggesting a strong interfacial adhesion be- tween the PLA matrix and the filler particles. For higher concentration of LNC (10-20 wt $\%)$, the presence of aggregates weakened the nanocomposite leading to a reduction of strain at break and maximum stress (UTS).

The gas barrier properties of the PLA matrix for $\mathrm{D}_{2}$, $\mathrm{N}_{2}$ and $\mathrm{CO}_{2}$ had been improved by increasing LCN concentration up to a critical value of $6.5 \mathrm{wt} \%$, for which the gas permeability of the nanocomposite was $70 \%$ lower than that of pure PLA film. At higher concentration of the filler, micrometer-sized LNC aggregates formed in the PLA matrix and the gas permeability of the nanocomposite increased. The enhancement of the gas barrier properties was attributed to the formation of rigidified polymer regions with size in the range of $8-10 \mathrm{~nm}$ around the dispersed LNC filler particles.

All the produced biopolymer nanocomposites exhibited a good transparency, and consequently evidenced a great potential for application in packaging technology when the preparation procedure ensured a high dispersion degree of the filler particles.

\section{References}

[1] Li W., Wu Q., Zhao X., Huang Z., Cao J., Li J., Liu S.: Enhanced thermal and mechanical properties of PVA composites formed with filamentous nanocellulose fibrils. Carbohydrate Polymers, 113, 403-410 (2014) https://doi.org/10.1016/j.carbpol.2014.07.031

[2] Sun J., Shen J., Chen S., Cooper M., Fu H., Wu D., Yang Z.: Nanofiller reinforced biodegradable PLA/PHA composites: Current status and future trends. Polymers, 10, 505/1-505/22 (2018) https://doi.org/10.3390/polym 10050505 
[3] Swaroop C., Shukla M.: Nano-magnesium oxide reinforced polylactic acid biofilms for food packaging applications. International Journal of Biological Macromolecules, 113, 729-736 (2018).

https://doi.org/10.1016/j.ijbiomac.2018.02.156

[4] Siracusa V., Rocculi P., Romani S., Rosa M. D.: Biodegradable polymers for food packaging: A review. Trends in Food Science and Technology, 19, 634-643 (2008). https://doi.org/10.1016/j.tifs.2008.07.003

[5] Huang Y., Mei L., Chen X., Wang Q.: Recent developments in food packaging based on nanomaterials. Nanomaterials, 8, 830/1-830/29 (2018).

https://doi.org/10.3390/nano8100830

[6] Aframehr W. M., Molki B., Heidarian P., Behzad T., Sadeghi M., Bagheri R.: Effect of calcium carbonate nanoparticles on barrier properties and biodegradability of polylactic acid. Fibers and Polymers, 18, 2041-2048 (2017).

https://doi.org/10.1007/s12221-017-6853-0

[7] Vasile C., Râpă M., Ştefan M., Stan M., Mavavei S., Darie-Niţă R., Barbu-Tudoran L., Vodnar D., Popa E. E., Ştefan R., Borodi G., Brebu M.: New PLA/ZnO:Cu/Ag bionanocomposites for food packaging. Express Polymer Letters, 11, 531-544 (2017).

https://doi.org/10.3144/expresspolymlett.2017.51

[8] Sanchez-Garcia M. D., Gimenez E., Lagaron J. M.: Morphology and barrier properties of solvent cast composites of thermoplastic biopolymers and purified cellulose fibers. Carbohydrate Polymers, 71, 235-244 (2008).

https://doi.org/10.1016/j.carbpol.2007.05.041

[9] Khan A., Khan R. A., Salmieri S., Tien C. L., Riedl B., Bouchard J., Chauve G., Tan V., Kamal M. R., Lacroix M.: Mechanical and barrier properties of nanocrystalline cellulose reinforced chitosan based nanocomposite films. Carbohydrate Polymers, 90, 1601-1608 (2012). https://doi.org/10.1016/j.carbpol.2012.07.037

[10] Lavoine N., Desloges I., Dufresne A., Bras J.: Microfibrillated cellulose - Its barrier properties and applications in cellulosic materials: A review. Carbohydrate Polymers, 90, 735-764 (2012).

https://doi.org/10.1016/j.carbpol.2012.05.026

[11] Espino-Pérez E., Bras J., Ducruet V., Guinault A., Dufresne A., Domenek S.: Influence of chemical surface modification of cellulose nanowhiskers on thermal, mechanical, and barrier properties of poly(lactide) based bionanocomposites. European Polymer Journal, 49, 3144-3154 (2013).

https://doi.org/10.1016/j.eurpolymj.2013.07.017

[12] Fortunati E., Peltzer M., Armentano I., Torre L., Jiménez A., Kenny J. M.: Effects of modified cellulose nanocrystals on the barrier and migration properties of PLA nano-biocomposites. Carbohydrate Polymers, 90, 948 956 (2012).

https://doi.org/10.1016/j.carbpol.2012.06.025
[13] Murariu M., Dubois P.: PLA composites: From production to properties. Advanced Drug Delivery Reviews, 107, 17-46 (2016).

https://doi.org/10.1016/j.addr.2016.04.003

[14] Georgiopoulos P., Kontou E., Georgousis G.: Effect of silane treatment loading on the flexural properties of PLA/flax unidirectional composites. Composites Communications, 10, 6-10 (2018).

https://doi.org/10.1016/j.coco.2018.05.002

[15] Georgiopoulos P., Christopoulos A., Koutsoumpis S., Kontou E.: The effect of surface treatment on the performance of flax/biodegradable composites. Composites Part B: Engineering, 106, 88-98 (2016).

https://doi.org/10.1016/j.compositesb.2016.09.027

[16] Rubio-López A., Artero-Guerrero J., Pernas-Sánchez J., Santiuste C.: Compression after impact of flax/PLA biodegradable composites. Polymer Testing, 59, 127-135 (2017).

https://doi.org/10.1016/j.polymertesting.2017.01.025

[17] Bax B., Müssig J.: Impact and tensile properties of PLA/Cordenka and PLA/flax composites. Composites Science and Technology, 68, 1601-1607 (2008).

https://doi.org/10.1016/j.compscitech.2008.01.004

[18] Saba N., Paridah M. T., Jawaid M.: Mechanical properties of kenaf fibre reinforced polymer composite: A review. Construction and Building Materials, 76, 8796 (2015).

https://doi.org/10.1016/j.conbuildmat.2014.11.043

[19] Nishino T., Hirao K., Kotera M., Nakamae K., Inagaki H.: Kenaf reinforced biodegradable composite. Composites Science and Technology, 63, 1281-1286 (2003). https://doi.org/10.1016/s0266-3538(03)00099-x

[20] Akil H. M., Omar M. F., Mazuki A. A. M., Safiee S., Ishak Z. A. M., Abu Bakar A.: Kenaf fiber reinforced composites: A review. Materials and Design, 32, 41074121 (2011).

https://doi.org/10.1016/j.matdes.2011.04.008

[21] de Assis F. S., Pereira A. C., da Costa Garcia Filho F., Lima É. P., Monteiro S. N., Weber R. P.: Performance of jute non-woven mat reinforced polyester matrix composite in multilayered armor. Journal of Materials Research and Technology, 7, 535-540 (2018).

https://doi.org/10.1016/j.jmrt.2018.05.026

[22] Basak R., Choudhury P. L., Pandey K. M.: Effect of temperature variation on surface treatment of short jute fiber-reinforced epoxy composites. Materials Today: Proceedings, 5, 1271-1277 (2018).

https://doi.org/10.1016/j.matpr.2017.11.211

[23] Lautenschläger M. I., Mayer L., Gebauer J., Weidenmann K. A., Henning F., Elsner P.: Comparison of fillerdependent mechanical properties of jute fiber reinforced sheet and bulk molding compound. Composite Structures, 203, 960-967 (2018).

https://doi.org/10.1016/j.compstruct.2017.09.100 
[24] Durante M., Formisano A., Boccarusso L., Langella A., Carrino L.: Creep behaviour of polylactic acid reinforced by woven hemp fabric. Composites Part B: Engineering, 124, 16-22 (2017).

https://doi.org/10.1016/j.compositesb.2017.05.038

[25] Ibrahim H., Farag M., Megahed H., Mehanny S.: Characteristics of starch-based biodegradable composites reinforced with date palm and flax fibers. Carbohydrate Polymers, 101, 11-19 (2014).

https://doi.org/10.1016/j.carbpol.2013.08.051

[26] Väisänen T., Das O., Tomppo L.: A review on new biobased constituents for natural fiber-polymer composites. Journal of Cleaner Production, 149, 582-596 (2017).

https://doi.org/10.1016/j.jclepro.2017.02.132

[27] Dufresne A.: Nanocellulose: A new ageless bionanomaterial. Materials Today, 16, 220-227 (2013).

https://doi.org/10.1016/j.mattod.2013.06.004

[28] Tashiro K., Kobayashi M.: Theoretical evaluation of three-dimensional elastic constants of native and regenerated celluloses: Role of hydrogen bonds. Polymer, 32, 1516-1526 (1991).

http://doi.org/10.1016/0032-3861(91)90435-L

[29] Eichhorn S. J., Dufresne A., Aranguren M., Marcovich N. E., Capadona J. R., Rowan S. J., Weder C., Thielemans W., Roman M., Renneckar S., Gindl W., Veigel S., Keckes J., Yano H., Abe K., Nogi M., Nakagaito A. N., Mangalam A., Simonsen J., Benight A. S., Bismarck A., Berglund L. A., Peijs T.: Review: Current international research into cellulose nanofibres and nanocomposites. Journal of Materials Science, 45, 1-33 (2009).

https://doi.org/10.1007/s10853-009-3874-0

[30] Lagerwall J. P. F., Schütz C., Salajkova M., Noh J., Park J. H., Scalia G., Bergström L.: Cellulose nanocrystalbased materials: From liquid crystal self-assembly and glass formation to multifunctional thin films. NPG Asia Materials, 6, 80-81 (2014).

https://doi.org/10.1038/am.2013.69

[31] Bondeson D., Mathew A., Oksman K.: Optimization of the isolation of nanocrystals from microcrystalline cellulose by acid hydrolysis. Cellulose, 13, 171-180 (2006). https://doi.org/10.1007/s10570-006-9061-4

[32] Li W., Zhao X., Huang Z., Liu S.: Nanocellulose fibrils isolated from BHKP using ultrasonication and their reinforcing properties in transparent poly(vinyl alcohol) films. Journal of Polymer Research, 20, 1-7 (2013). https://doi.org/10.1007/s10965-013-0210-9

[33] Cherian B. M., Leão A. L., de Souza S. F., Thomas S., Pothan L. A., Kottaisamy M.: Isolation of nanocellulose from pineapple leaf fibres by steam explosion. Carbohydrate Polymers, 81, 720-725 (2010).

https://doi.org/10.1016/j.carbpol.2010.03.046

[34] Chen W., Yu H., Liu Y., Chen P., Zhang M., Hai Y.: Individualization of cellulose nanofibers from wood using high-intensity ultrasonication combined with chemical pretreatments. Carbohydrate Polymers, 83, 1804-1811 (2011).

https://doi.org/10.1016/j.carbpol.2010.10.040
[35] Dubey S., Sharma R. K., Agarwal P., Singh J., Sinha N., Singh R. P.: From rotten grapes to industrial exploitation: Komagataeibacter europaeus SGP37, a micro-factory for macroscale production of bacterial nanocellulose. International Journal of Biological Macromolecules, 96, 52-60 (2017).

https://doi.org/10.1016/j.ijbiomac.2016.12.016

[36] Salajková M., Berglund L. A., Zhou Q.: Hydrophobic cellulose nanocrystals modified with quaternary ammonium salts. Journal of Materials Chemistry, 22, 197198 (2012).

https://doi.org/10.1039/c2jm34355j

[37] Fortunati E., Luzi F., Puglia D., Petrucci R., Kenny J. M., Torre L.: Processing of PLA nanocomposites with cellulose nanocrystals extracted from Posidonia oceanica waste: Innovative reuse of coastal plant. Industrial Crops and Products, 67, 439-447 (2015).

https://doi.org/10.1016/j.indcrop.2015.01.075

[38] Johari A. P., Kurmvanshi S. K., Mohanty S., Nayak S. K.: Influence of surface modified cellulose microfibrils on the improved mechanical properties of poly(lactic acid). International Journal of Biological Macromolecules, 84, 329-339 (2016).

https://doi.org/10.1016/j.ijbiomac.2015.12.038

[39] Tsou C-H., Hung W-S., Wu C-S., Chen J-C., Huang C-Y., Chiu S-H., Tsou C-Y., Yao W-H., Lin S-M., Chu C-K., Hu C-C., Lee K-R., Suen M-C.: New composition of maleic-anhydride-grafted poly(lactic acid)/rice husk with methylenediphenyl diisocyanate. Materials Science, 20, 446-451 (2014). https://doi.org/10.5755/j01.ms.20.4.6034

[40] Hwang S. W., Lee S. B., Lee C. K., Lee J. Y., Shim J. K., Selke S. E. M., Soto-Valdez H., Matuana L., Rubino M., Auras R.: Grafting of maleic anhydride on poly(L-lactic acid). Effects on physical and mechanical properties. Polymer Testing, 31, 333-344 (2012). https://doi.org/10.1016/j.polymertesting.2011.12.005

[41] Hassouna F., Raquez J-M., Addiego F., Toniazzo V., Dubois P., Ruch D.: New development on plasticized poly(lactide): Chemical grafting of citrate on PLA by reactive extrusion. European Polymer Journal, 48, 404415 (2012).

https://doi.org/10.1016/j.eurpolymj.2011.12.001

[42] Csikós Á., Faludi G., Domján A., Renner K., Móczó J., Pukánszky B.: Modification of interfacial adhesion with a functionalized polymer in PLA/wood composites. European Polymer Journal, 68, 592-600 (2015).

https://doi.org/10.1016/j.eurpolymj.2015.03.032

[43] Detyothin S., Selke S. E. M., Narayan R., Rubino M., Auras R.: Reactive functionalization of poly(lactic acid), PLA: Effects of the reactive modifier, initiator and processing conditions on the final grafted maleic anhydride content and molecular weight of PLA. Polymer Degradation and Stability, 98, 2697-2708 (2013). https://doi.org/10.1016/j.polymdegradstab.2013.10.001 
[44] Yu T., Jiang N., Li Y.: Study on short ramie fiber/ poly(lactic acid) composites compatibilized by maleic anhydride. Composites Part A: Applied Science and Manufacturing, 64, 139-146 (2014).

https://doi.org/10.1016/j.compositesa.2014.05.008

[45] Wang H-M., Chou Y-T., Wu C-S., Yeh J-T.: Polyester/ cellulose acetate composites: Preparation, characterization and biocompatible. Journal of Applied Polymer Science, 126, 242-251 (2012). https://doi.org/10.1002/app.36965

[46] Lu Y., Cueva M. C., Lara-Curzio E., Ozcan S.: Improved mechanical properties of polylactide nanocomposites-reinforced with cellulose nanofibrils through interfacial engineering via amine-functionalization. Carbohydrate Polymers, 131, 208-217 (2015).

https://doi.org/10.1016/j.carbpol.2015.05.047

[47] Lizundia E., Fortunati E., Dominici F., Vilas J. L., León L. M., Armentano I., Torre L., Kenny J. M.: PLLA-grafted cellulose nanocrystals: Role of the CNC content and grafting on the PLA bionanocomposite film properties. Carbohydrate Polymers, 142, 105-113 (2016).

https://doi.org/10.1016/j.carbpol.2016.01.041

[48] Gibson L. J.: The hierarchical structure and mechanics of plant materials. Journal of the Royal Society Interface, 9, 2749-2766 (2012). https://doi.org/10.1098/rsif.2012.0341

[49] Roilo D., Maestri C., Scarpa M., Bettotti P., Checchetto R.: Gas barrier and optical properties of cellulose nanofiber coatings with dispersed $\mathrm{TiO}_{2}$ nanoparticles. Surfaces and Coatings Technologies, 343, 131-137 (2017). https://doi.org/10.1016/j.surfcoat.2017.10.015

[50] Roilo D., Maestri C. A., Scarpa M., Bettotti P., Egger W., Koschine T., Brusa R. S., Checchetto R.: Cellulose nanofibrils films: Molecular diffusion through elongated sub-nano cavities. The Journal of Physical Chemistry C, 121, 15437-15447 (2017). https://doi.org/10.1021/acs.jpcc.7b02895

[51] Fortunati E., Armentano I., Zhou Q., Iannoni A., Saino E., Visai L., Berglund L. A., Kenny J. M.: Multifunctional bionanocomposite films of poly(lactic acid), cellulose nanocrystals and silver nanoparticles. Carbohydrate Polymers, 87, 1596-1605 (2012).

https://doi.org/10.1016/j.carbpol.2011.09.066

[52] González A., Alvarez Igarzabal C. I.: Soy protein poly(lactic acid) bilayer films as biodegradable material for active food packaging. Food Hydrocolloids, 33, 289-296 (2013).

https://doi.org/10.1016/j.foodhyd.2013.03.010

[53] Ramos M., Jiménez A., Peltzer M., Garrigós M. C.: Development of novel nano-biocomposite antioxidant films based on poly (lactic acid) and thymol for active packaging. Food Chemistry, 162, 149-155 (2014). https://doi.org/10.1016/j.foodchem.2014.04.026

[54] Chang P. R., Jian R., Zheng P., Yu J., Ma X.: Preparation and properties of glycerol plasticized-starch (GPS)/ cellulose nanoparticle $(\mathrm{CN})$ composites. Carbohydrate Polymers, 79, 301-305 (2010).

https://doi.org/10.1016/j.carbpol.2009.08.007
[55] Goetz L., Mathew A., Oksman K., Gatenholm P., Ragauskas A. J.: A novel nanocomposite film prepared from crosslinked cellulosic whiskers. Carbohydrate Polymers, 75, 85-89 (2009). https://doi.org/10.1016/j.carbpol.2008.06.017

[56] Shavisi N., Khanjari A., Basti A. A., Misaghi A., Shahbazi Y.: Effect of PLA films containing propolis ethanolic extract, cellulose nanoparticle and Ziziphora clinopodioides essential oil on chemical, microbial and sensory properties of minced beef. Meat Science, 124, 95-104 (2017).

https://doi.org/10.1016/j.meatsci.2016.10.015

[57] Fischer E. W., Sterzel H. J., Wegner G.: Investigation of the structure of solution grown crystals of lactide copolymers by means of chemical reactions. KolloidZeitschrift und Zeitschrift für Polymere, 251, 980-990 (1973). https://doi.org/10.1007/bf01498927

[58] Silverstein R. M.: Spectrometric identification of organic compounds. Wiley, Chichester (1992).

[59] Checchetto R., Bettotti P., Brusa R. S., Carotenuto G., Egger W., Hugenschmidt C., Miotello A.: Anomalous molecular infiltration in graphene laminates. Physical Chemistry Chemical Physics, 20, 24671-24680 (2018). https://doi.org/10.1039/C8CP03879A

[60] Yarwood J.: The physical basis of ultrahigh vacuum. Physics Bulletin, 20, 383-389 (1969). https://doi.org/10.1088/0031-9112/20/9/026

[61] Khoo R. Z., Ismail H., Chow W. S.: Thermal and morphological properties of poly (lactic acid)/nanocellulose nanocomposites. Procedia Chemistry, 19, 788-794 (2016).

https://doi.org/10.1016/j.proche.2016.03.086

[62] Dorigato A., Sebastiani M., Pegoretti A., Fambri L.: Effect of silica nanoparticles on the mechanical performances of poly(lactic acid). Journal of Polymers and the Environment, 20, 713-725 (2012). https://doi.org/10.1007/s10924-012-0425-6

[63] Arrieta M. P., Fortunati E., Dominici F., López J., Kenny J. M.: Bionanocomposite films based on plasticized PLA-PHB/cellulose nanocrystal blends. Carbohydrate Polymers, 121, 265-275 (2015). https://doi.org/10.1016/j.carbpol.2014.12.056

[64] Spinella S., Lo Re G., Liu B., Dorgan J., Habibi Y., Leclère P., Raquez J-M., Dubois P., Gross R. A.: Polylactide/cellulose nanocrystal nanocomposites: Efficient routes for nanofiber modification and effects of nanofiber chemistry on PLA reinforcement. Polymer, 65, 917 (2015). https://doi.org/10.1016/j.polymer.2015.02.048

[65] Fambri L., Penati A., Kolarik J.: Modification of polycarbonate with miscible polyurethane elastomers. Polymer, 38, 835-843 (1997).

https://doi.org/10.1016/S0032-3861(96)00562-9 
[66] Kelnar I., Kratochvíl J., Kaprálková L., Zhigunov A., Padovec Z., Růžička M., Nevoralová M.: Antagonistic effects on mechanical properties of microfibrillar composites with dual reinforcement: Explanation by FEA model of soft interface. Journal of Applied Polymer Science, 134, 44712/1-44712/9 (2017).

https://doi.org/10.1002/app.44712

[67] Suryanegara L., Nakagaito A., Yano H.: The effect of crystallization of PLA on the thermal and mechanical properties of microfibrillated cellulose-reinforced PLA composites. Composites Science and Technology, 69, 1187-1192 (2009).

https://doi.org/10.1016/j.compscitech.2009.02.022

[68] Kolařík J., Pegoretti A.: Proposal of the Boltzmann-like superposition principle for nonlinear tensile creep of thermoplastics. Polymer Testing, 27, 596-606 (2008). https://doi.org/10.1016/j.polymertesting.2008.03.002

[69] Dorigato A., Pegoretti A., Kolařík J.: Nonlinear tensile creep of linear low density polyethylene/fumed silica nanocomposites: Time-strain superposition and creep prediction. Polymer Composites, 31, 1947-1955 (2010). https://doi.org/10.1002/pc.20993

[70] Merkel T., Pinnau I., Prabhakar R., Freeman B.: Gas and vapor transport properties of perfluoropolymers. in 'Materials science of membranes for gas and vapor separation' (eds: Yampolskii Y., Pinnau I., Freeman B.) Wiley, Chichester 251-270 (2006).

https://doi.org/10.1002/047002903X.ch9

[71] Crank J.: The mathematics of diffusion. Oxford Science Publications (1986).

[72] Bhatia A., Gupta R. K., Bhattacharya S. N., Choi H. J.: Analysis of gas permeability characteristics of poly(lactic acid)/poly(butylene succinate) nanocomposites. Journal of Nanomaterials, 11, 249094/1-249094/11 (2012). https://doi.org/10.1155/2012/249094
[73] Nielsen L. E.: Models for the permeability of filled polymer systems. Journal of Macromolecular Science Part A: Chemistry, 1, 929-942 (1967). https://doi.org/10.1080/10601326708053745

[74] Bharadwaj R. K.: Modeling the barrier properties of polymer-layered silicate nanocomposites. Macromolecules, 34, 9189-9192 (2001).

https://doi.org/10.1021/ma010780b

[75] Aroon M. A., Ismail A. F., Matsuura T., Montazer-Rahmati M. M.: Performance studies of mixed matrix membranes for gas separation: A review. Separation and $\mathrm{Pu}-$ rification Technology, 75, 229-242 (2010). https://doi.org/10.1016/j.seppur.2010.08.023

[76] Pal R.: Permeation models for mixed matrix membranes. Journal of Colloid and Interface Science, 317, 191-198 (2008). https://doi.org/10.1016/j.jcis.2007.09.032

[77] Moore T. T., Koros W. J.: Non-ideal effects in organicinorganic materials for gas separation membranes. Journal of Molecular Structure, 739, 87-98 (2005). https://doi.org/10.1016/j.molstruc.2004.05.043

[78] Rezakazemi M., Amooghin A. E., Mehdi MontazerRahmati M., Ismail A., Matsuura T.: State-of-the-art membrane based $\mathrm{CO}_{2}$ separation using mixed matrix membranes (MMMs): An overview on current status and future directions. Progress in Polymer Science, 39, 817-861 (2014). https://doi.org/10.1016/j.progpolymsci.2014.01.003

[79] Roilo D., Patil P., Brusa R. S., Miotello A., Aghion S., Ferragut R., Checchetto R.: Polymer rigidification in graphene based nanocomposites: Gas barrier effects and free volume reduction. Polymer, 121, 17-25 (2017). https://doi.org/10.1016/j.polymer.2017.06.010 